\title{
Article \\ Persulfidation of Nitrate Reductase 2 Is Involved in L-Cysteine Desulfhydrase-Regulated Rice Drought Tolerance
}

\author{
Heng Zhou ${ }^{1}$, Ying Zhou ${ }^{1}$, Feng Zhang ${ }^{1}$, Wenxue Guan ${ }^{1}$, Ye Su ${ }^{1}$, Xingxing Yuan ${ }^{2}$ and Yanjie Xie ${ }^{1, * \mathbb{D}}$ \\ 1 Laboratory Center of Life Sciences, College of Life Sciences, Nanjing Agricultural University, \\ Nanjing 210095, China; hengzhou@njau.edu.cn (H.Z.); 2020116101@stu.njau.edu.cn (Y.Z.); \\ 2018116103@njau.edu.cn (F.Z.); 2016116114@njau.edu.cn (W.G.); 2017116117@njau.edu.cn (Y.S.) \\ 2 Institute of Industrial Crops, Jiangsu Academy of Agricultural Sciences, Nanjing 210014, China; \\ yxx@jaas.ac.cn \\ * Correspondence: yjxie@njau.edu.cn
}

Citation: Zhou, H.; Zhou, Y.; Zhang, F.; Guan, W.; Su, Y.; Yuan, X.; Xie, Y.

Persulfidation of Nitrate Reductase 2 Is Involved in L-Cysteine Desulfhydrase-Regulated Rice Drought Tolerance. Int. J. Mol. Sci. 2021, 22, 12119. https://doi.org/ $10.3390 /$ ijms 222212119

Academic Editor: Kenji Miura

Received: 22 September 2021

Accepted: 5 November 2021

Published: 9 November 2021

Publisher's Note: MDPI stays neutral with regard to jurisdictional claims in published maps and institutional affiliations.

Copyright: (c) 2021 by the authors. Licensee MDPI, Basel, Switzerland. This article is an open access article distributed under the terms and conditions of the Creative Commons Attribution (CC BY) license (https:// creativecommons.org/licenses/by/ $4.0 /)$.

\begin{abstract}
Hydrogen sulfide $\left(\mathrm{H}_{2} \mathrm{~S}\right)$ is an important signaling molecule that regulates diverse cellular signaling pathways through persulfidation. Our previous study revealed that $\mathrm{H}_{2} \mathrm{~S}$ is involved in the improvement of rice drought tolerance. However, the corresponding enzymatic sources of $\mathrm{H}_{2} \mathrm{~S}$ and its regulatory mechanism in response to drought stress are not clear. Here, we cloned and characterized a putative L-cysteine desulfhydrase $(L C D)$ gene in rice, which encodes a protein possessing $\mathrm{H}_{2} \mathrm{~S}$-producing activity and was named OsLCD1. Overexpression of OsLCD1 results in enhanced $\mathrm{H}_{2} \mathrm{~S}$ production, persulfidation of total soluble protein, and confers rice drought tolerance. Further, we found that nitrate reductase (NR) activity was decreased under drought stress, and the inhibition of NR activity was controlled by endogenous $\mathrm{H}_{2} \mathrm{~S}$ production. Persulfidation of NIA2, an NR isoform responsible for the main NR activity, led to a decrease in total NR activity in rice. Furthermore, drought stress-triggered inhibition of NR activity and persulfidation of NIA2 was intensified in the OsLCD1 overexpression line. Phenotypical and molecular analysis revealed that mutation of NIA2 enhanced rice drought tolerance by activating the expression of genes encoding antioxidant enzymes and ABA-responsive genes. Taken together, our results showed the role of OsLCD1 in modulating $\mathrm{H}_{2} \mathrm{~S}$ production and provided insight into $\mathrm{H}_{2} \mathrm{~S}$-regulated persulfidation of NIA2 in the control of rice drought stress.
\end{abstract}

Keywords: hydrogen sulfide; persulfidation; drought stress; nitrate reductase; L-cysteine desulfhydrase

\section{Introduction}

Drought is the most widespread and damaging of all environmental stresses, restricting global crop production and food security [1]. Plants can mitigate the effects of drought through the collaboration of complex signal networks. It is well documented that maintaining redox homeostasis and activating $\mathrm{ABA}$ signaling could improve plant drought stress tolerance [2,3]. Hydrogen sulfide $\left(\mathrm{H}_{2} \mathrm{~S}\right)$ has been recognized as a newly gaseous signaling molecule in both animals and plants $[4,5]$. During the past decades, numerous studies have suggested that $\mathrm{H}_{2} \mathrm{~S}$ is involved in various developmental and stress response processes during the whole lifespan in plants [6-9]. For example, $\mathrm{H}_{2} \mathrm{~S}$ is involved in the improvement of drought tolerance by interacting with abscisic acid (ABA) and ion fluxes, thus regulating stomal movement and downstream genes expression in Arabidopsis [10,11]. Pretreatment with exogenous $\mathrm{NaHS}\left(\mathrm{a} \mathrm{H}_{2} \mathrm{~S}\right.$ donor) alleviates drought stress responses by increasing $\mathrm{ABA}$ levels through the expression of $\mathrm{ABA}$ synthesis genes in wheat and rice $[12,13]$. Although those studies have demonstrated that $\mathrm{H}_{2} \mathrm{~S}$ is involved in regulating many metabolic processes or improving plant tolerance to abiotic stresses, they mainly rely on exogenous application of $\mathrm{H}_{2} \mathrm{~S}$ donors, scavengers, and inhibitors to manipulate endogenous $\mathrm{H}_{2} \mathrm{~S}$ content $[13,14]$. 
In plants, cysteine desulfhydrases (CDes) are one of the most important clusters of $\mathrm{H}_{2} \mathrm{~S}$-producing enzymes catalyzing the degradation of cysteine into $\mathrm{H}_{2} \mathrm{~S}$, pyruvate, and ammonium [15]. There are two types of CDes in plants: L-cysteine desulfhydrase (LCD) and D-cysteine desulfhydrase (DCD) with L-cysteine (L-Cys) or D-cysteine (D-Cys) as substrate, respectively [16]. $\mathrm{H}_{2} \mathrm{~S}$ can also be generated as a side reaction of cysteine biosynthesis catalyzed by serine acetyltransferase (SAT) and O-acetyl-serine(thiol)lyase (OAS-TL) [17,18]. Interestingly, an OAS-TL isoform CYSTEINE SYNTHASE (CS)-LIKE protein (CS-LIKE) has been reported that actually catalyzes the desulfuration of L-Cys to $\mathrm{H}_{2} \mathrm{~S}$ plus ammonia and pyruvate [18]. Thus, CS-LIKE is a novel L-cysteine desulfhydrase and has been designated as DES1. In Arabidopsis, LCD and DES1-mediated endogenous $\mathrm{H}_{2} \mathrm{~S}$ production has been widely reported as an important role in facilitating tolerance to various environmental stimuli, including heavy metal and drought stress [11,18-20]. However, to date, little information is available about the LCD in rice. A recent study revealed that a putative rice L-cysteine desulfhydrase $L C D$ actually encodes a true L-cysteine synthetase [21], suggesting the enzymatic sources of endogenous $\mathrm{H}_{2} \mathrm{~S}$ production still need to be further explored.

Signaling by $\mathrm{H}_{2} \mathrm{~S}$ is proposed to occur via persulfidation, the oxidative post-translational modification of protein Cys residues (R-SHs) by covalent addition of thiol groups to form persulfides (R-SSHs) $[9,22]$. Persulfidation modulates protein functions by affecting its biochemical activity and subcellular distribution, thus providing a robust and flexible mechanism for biological regulation in response to metabolic stimuli and environmental cues [23,24]. Recently, by using a comparative and label-free quantitative proteomic analysis approach, almost $13 \%$ of the entire annotated proteome proteins were identified as being persulfidated in Arabidopsis [23,25]. These proteins are involved in a wide range of biological functions, regulating important processes such as primary metabolism, plant responses to stresses, growth and development, RNA translation, and protein degradation. In guard cells, a complex interaction of $\mathrm{H}_{2} \mathrm{~S}$-mediated persulfidation and $\mathrm{ABA}$ signaling has also been described. In the presence of ABA, L-cysteine desulfhydrase1 (DES1) is activated by $\mathrm{H}_{2} \mathrm{~S}$ through persulfidation resulting in a burst of $\mathrm{H}_{2} \mathrm{~S}$ in guard cells [26]. The increase in $\mathrm{H}_{2} \mathrm{~S}$, in turn, facilitates the over-accumulation of $\mathrm{ROS}$ via persulfidation of the NADPH oxidase RESPIRATORY BURST OXIDASE HOMOLOG D(RBOHD), thereby inducing stomatal closure [26]. Besides that, $\mathrm{H}_{2} \mathrm{~S}$-induced persulfidation of ABSCISIC INSENSITIVE 4 (ABI4) is involved in the ABA signaling pathway [27]. These results clearly indicated that $\mathrm{H}_{2} \mathrm{~S}$ exerts its biological function through precisely persulfidation of target protein in plants. Previously, we found that exogenous application of NaHS could significantly improve rice drought tolerance by reestablishing redox homeostasis and activation of ABA biosynthesis and signaling [13]. However, the underlying regulatory mechanisms of endogenous $\mathrm{H}_{2} \mathrm{~S}$ are not clear.

Nitrate reductase (NR) is a key enzyme in plant nitrogen assimilation, which catalyzes the reduction in nitrate to nitrite in plants [28]. NR plays an important role in plant response to a variety of biotic and abiotic stresses [29]. A study in Arabidopsis showed the rate of water loss due to water transpiration was significantly slower in nia1/nia2 double mutant than in wild-type plants, with nia1/nia2 double mutant showing the higher expression of ABA-responsive genes and drought tolerance [30], demonstrating plant drought tolerance is negatively regulated by $N R$ abundance.

The aim of this study is to explore and characterize the enzymatic sources of endogenous $\mathrm{H}_{2} \mathrm{~S}$ production and elucidate the underlying mechanism of how $\mathrm{H}_{2} \mathrm{~S}$ confers rice drought tolerance. We cloned and characterized the function of a true $L C D$ (OsLCD1) from rice. The corresponding biochemical characteristics of purified LCD1 proteins showed that this enzyme predominantly processes $\mathrm{H}_{2} \mathrm{~S}$ producing activity. We found that overexpression of OSLCD1 enhanced rice drought tolerance by activating the expression of related genes encoding antioxidant enzymes and ABA-responsive gene. Further, we demonstrated that persulfidation of NIA2, an NR isoform responsible for the main NR activity, led to a decrease in total NR activity, thus controlling the above genes expression. By combining genetic and molecular analysis, we provide evidence here that $\mathrm{H}_{2} \mathrm{~S}$ might 
through, at least partially, persulfidation-mediated inhibition of NR activity to improve rice drought tolerance.

\section{Results}

\subsection{Cloning and Functional Characterization of the OsLCD}

In order to characterize the putative LCD protein in rice plants, the Arabidopsis LCD (At3g62130) was used as a query sequence to search the homologous gene in Oryza sativa by using uniprot-BLAST (https:/ / www.ncbi.nlm.nih.gov/, accessed on 10 July 2019). We found a putative L-cysteine desulfhydrase (OsLCD1, LOC_Os01g18640) sharing the highest similarity (56\%) with AtLCD, which encode an OsLCD protein with 482 amino acids residues (Figure 1). The molecular mass of OsLCD1 is $55 \mathrm{kDa}$, and the theoretical isoelectric point is 5.836 (http://isoelectric.ovh.org, accessed on 20 July 2019). Subsequently, the sequences alignment of the OsLCD1 and CDes homology and OAS-TL family proteins from other species were performed. The results showed that OsLCD1 shares a higher sequence identity with CDes homology from Panicum miliaceum, Dichanthelium oligosanthes, Zea mays, and Arabidopsis thaliana in comparison with that of OAS-TL family members from Arabidopsis thaliana, including AtDES1. Furthermore, the phylogenetic tree and homology tree were created with MAGE and DNAMAN software with default parameters, respectively. Among those proteins, OsLCD1 is more closely related to the LCD homology proteins from plants (Figure S1).

To validate the biochemical properties of OsLCD1, the corresponding full-length cDNA was cloned, and the recombinant OsLCD1 protein was expressed in E. coli as a $6 \times$ His N-terminally tagged fusion protein using $p E T-28 a(+)$ vector. The OsLCD1 fusion protein was purified by nickel affinity chromatography using nickel-nitrilotriacetic acid agarose (Ni-NAT) under non-denaturing conditions to preserve the enzymatic activity. A band appeared in the SDS-PAGE gel at the position corresponding to that of the Histagged OsLCD1 protein (55 kDa, Figure 2A). The band size and specificity of the OsLCD1 protein were further verified by Western blot analysis using His antibody (Figure 2B). We were able to recover $0.14 \mathrm{mg}$ purified protein per $150 \mathrm{~mL}$ of $E$. coli culture with a yield of $36.33 \%$ (Table 1). To confirm OsLCD1 functioned as a true LCD, the LCD and OASTL activities of both bacterial extracts and purified recombinant OsLCD1 protein were detected, respectively. As shown in Table 1, after purification, the specific LCD or OAS-TL activity (nmol/min/mg pro) of OsLCD1 protein changed from 8.02 or 1900 to 23.93 or 720 , with a corresponding purification factor of 2.98 and 0.38 . These results suggested that purified OsLCD1 protein might predominately catalyze the degradation of L-cysteine, and the OAS-TL reaction might be a side reaction. This proposition was also reinforced by the results of $\mathrm{Km}$ value, showing that the $\mathrm{Km}$ for OAS or $\mathrm{Na}_{2} \mathrm{~S}$ in the OAS-TL reaction is 25- or 54-fold higher than that for L-cysteine in LCD-catalytic reaction (Table 2), further suggesting a much higher affinity of OsLCD1 for L-cysteine as a substrate. Subsequently, biochemical analysis showed that the optimum temperature range of purified OsLCD1 protein was 50 to $80^{\circ} \mathrm{C}$ (Figure 2C). The rate of the $\mathrm{LCD}$ reaction increased to its maximum value at a temperature of $60^{\circ} \mathrm{C}$ and declined thereafter. Meanwhile, the LCD activity of OsLCD1 under different $\mathrm{pH}$ was determined at $60^{\circ} \mathrm{C}$, and results showed that the optimal $\mathrm{pH}$ of OsDCD1 was 9.5 (Figure 2D). 


Oryza sativa.seq
Panicum miliaceum.seq
Dichanthelium oligosanthes.seq
Zea mays.seq
AtLCD1.seq
AtDES.seq
OASTL-A.seq
OASTL-B.seq
OASTL-C.seq
Consensus
Oryza sativa.seq
Panicum miliaceum.seq
Dichanthelium oligosanthes.seq
Zea mays.seq
AtLCD1.seq
AtDES.seq
OASTL-A.seq
OASTL-B.seq
OASTL-C.seq
Consensus
Oryza sativa.seq
Panicum miliaceum.seq
Dichanthelium oligosanthes.seq
Zea mays.seq
AtLCD1.seq
AtDES.seq
OASTL-A.seq
OASTL-B.seq
OASTL-C.seq
Consensus

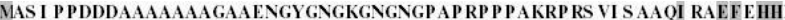

Oryza sativa.seq Panicum miliaceum.seq Dichanthelium oligosanthes.seq Zea mays.seq AtLCDiseq AtDES.seq OASTL-A.sed OASTL-B.seq OASTL-C.sed

Consensus

Oryza sativa.seq
Panicum miliaceum.sed Dichanthelium oligosanthes.sed Zea mays.seq AtDES.seq

OASTL-A.seq

OASTL-B.seq OASTL-C.seC Consensus

Oryza sativa.seq Panicum miliaceum.seq Dichanthelium oligosanthes.seq Zea mays.seq AtDES.seg OASTL-A.sed OASTL-B.seq OASTL-C.sed Consensus

Oryza sativa.seq Panicum miliaceum.seq Dichanthelium oligosanthes.sef Zea mays.seq AtLCD1.sed AtDES.seq OASTL-A.seq OASTL-B.sed Consensus

Oryza sativa.seq Panicum miliaceum.seq Dichanthelium oligosanthes.sec Zea mays.seq AtLCDi.sed AIDES.seq OASTL-A.seq OASTL-B.seq OASTL-C.

Oryza sativa.seq Panicum miliaceum.seq Dichanthelium oligosanthes.sed Zea mays.seq
AtLCD1.seq

AtDES.seq

OASTL-A.seq OASTL-B.sed OASTL-C.seC

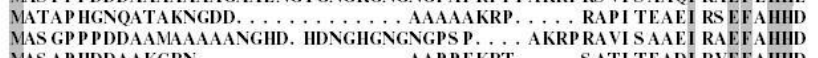

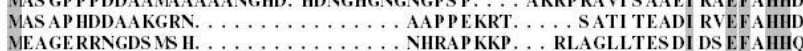

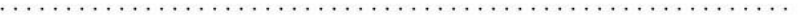

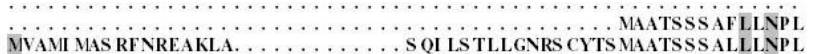

AGVARVNNGS FGCCPSS LEDAQARWQRLFI AQPDDFYF HALQP GLRRS RAAVAGLVNAGD GAVARVN NGTF GCCPATVLAARARWQRLF LS QPDAFYF HS LOP GLARS RAAVAAAVGAG AA AR NGSF GCCPAS LAAQAHORLFLAQPDAF YF HGLQQGLLRS RAAVAGAVGAG TGVARI NNGS EGCCPGS VLEAQRE WQLRYLRQPDEFYFNGLRRGLLAS RTVI SDLI NADD

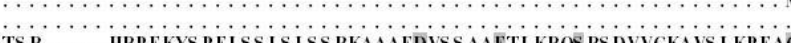
TSR. . HRPF KYS PELSS LS LSS RKAAAFDVSS AAFTLKRQS RSDVVCKAVS I KPEAG TSSSSSSTLRRFCSPEISS LSFSSASDFS LANKRQS RSFADGS ERDPS VVCEAVKRETG VAEVS LVDNATTAAAI VLQHAAUS FAEGRFS RGDAVLMLHYAYGA R RAYVARAGAT SS EVS LVDNATTAAAI VMQHVA US FAEGAFARGDAVLMLHYTYSS KS II HAYAARAGAT VS EVS LVDNATTAAAI VLQHAAIS FAEGHYARGDAVLML HYAYGA K S I HAYVARAGAT

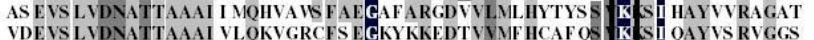
EDRVLI KNDVTELI GNTPMVYLNKI VDGCVARI AAKLENMEPCS MASRI AKDVIELI GNTPLVYLNNVAEGCVGRVAKLENMEPCS S RII GFS SI SDAE. VEGLNI ADNAAQLI GKTPMVYLNNVVKGCVAS VAAKL EI MEPCCS R RII GYS MI TDAE. PDLNI ADNVS QLI GKTP MVYLNSI AKGCVANI AAKLEI MEPCCS RI GYS NVTDAE.

\begin{tabular}{l|}
60 \\
42
\end{tabular}

55 L-CDes homology 41 I AtLCD1 \begin{tabular}{l|l}
41 & AtLCD \\
0 & AtDBS
\end{tabular} \begin{tabular}{l|l}
0 & \\
14 & OAS-TL
\end{tabular}

120 \begin{tabular}{l|l}
102 & L-CDes homology
\end{tabular} 101 I AtLCDI 1 AtDBS \begin{tabular}{l|l}
0 & \\
69 & OAS-TL
\end{tabular} \begin{tabular}{l|l}
180 & \\
162 & L-CDes homology \\
175 & L-C
\end{tabular} 161 AtLCD1 60 AtDBS \begin{tabular}{c|c}
58 & \\
128 & OAS-TL
\end{tabular}

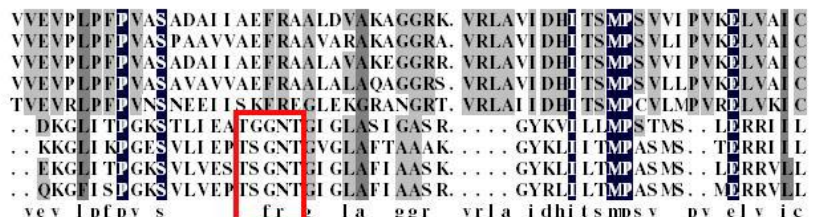
\begin{tabular}{l|l}
239 & \\
221 & L-CDes homology
\end{tabular} 220 AtLCD1 111 I AtDES \begin{tabular}{l|l}
109 & \\
179 & OAS-TL
\end{tabular} la ger vrla idhicsmps piers ic

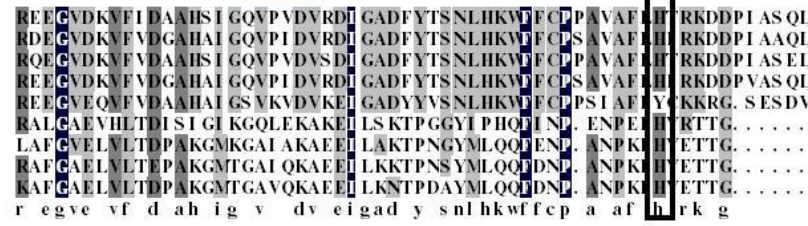
\begin{tabular}{l|l}
299 & \\
281 & L-CDes homology \\
294 & \\
278 & \\
279 & AtLCD1 \\
164 & AtDBS \\
162 & \\
232 & OAS-TL \\
270 &
\end{tabular}

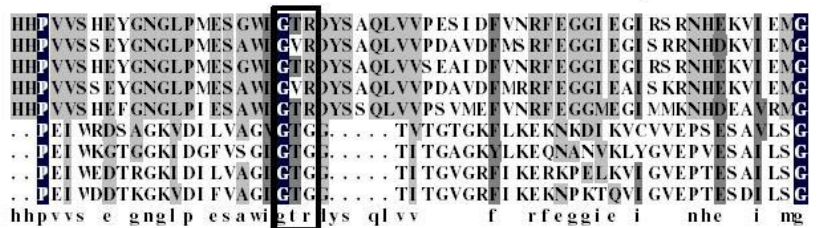
\begin{tabular}{l|l}
359 & \\
341 & L-CDes homology \\
354 & L-CD \\
338 &
\end{tabular} 339 I AtLCD1 217 AtDBS \begin{tabular}{l|l}
215 & OAS-TL \\
323 & OAS-TL
\end{tabular} KMLAEA WGTF LGTPPE LCGS MVMVGLPGCLGVESDDDVMRNRTMLRKDFNVEVPI YYNS AMLAEA WGTF LGS P PEMCGS MVMI GLPGCLGI DSDDDAMRVRDMLRNDF KVEVPI FNNS RMLAEA WGTFLGS P PLCGS MVNVGLP GCLGI ES DDD ANRVRTILRKDF HVEVPI YYNS.
TMLAEA WGTF LGS PPEMCGS MANVGLPGCLGI ESDDDAMRVRDILROF KVEVPI FNNS TMLAEA WGTF LG P PEMCGS MANVGLP GCLGI ES DDDANRVRDNLRNOF KVEVPI FNNS.
LMLADA WGTNLES P PEMCVGMVMI GLPS KLCVGSDEDAI KLRS YLRVHYS VEVPVFYLG. GKPGP HLI QGI GS. . GEI PANLDLSI VDEI I QVTGEEAI ETTKLLAI KEGLLVGISS GAS GKPGP HLI QGI ES. . GEI PANLDLSI VDEI I QVTGEEAI ETT KLLAI KEGLLVGISS GAS
GKPGP HKI QGI GA. . GFI PS VLNVDLI DEVVQVSSDESI DMAROLALKEGLLVGISS GAA GKP GP HKI QGI GA. . GF VP KNLDLAI VDEYI AI SS EEAI ETS KOLALQEGLLVGISS GAA GKPGP HKI QGI GA. . GFI P KNLDQKI NDEVI AI SSEEAI ETAKOLALKEGLMGISS GAA \begin{tabular}{l|l}
418 & \\
400 & L-CDes homology \\
413 & Lig
\end{tabular} 308 I AtLCD1 275 AtDES 273 \begin{tabular}{l|l}
381 & OAS-TL
\end{tabular} RRVEA. OEMAKDKNGDAVTGYVRI $\bar{S}$ HQVȲNVTEDYE KLEDAVNKLVADGFTSS KLRPS $Q$ TS VDGOEEMAKDANGDOVTGYVRI S HOVYNVRE EYEVLEDAVNKLVLDGFS CS KLRPS G RRVEG. OEMAKDKS GDPVTGHVRI SNQVYNVREDYERLEDAVHKLVSEGFTSS KL WPSE TS VEE GOEMAK. . . GDQVTGYVRI S HQVYNVTEEYEVLEDAVGKLVLDGFS CTKL RPS E . LRDGE EGVKD KDS GLI TAYVRI S HOVYNKTEDYERLRDAI TE LVKDQNTCQNLPAL. AAAALKVAKRPEN. VGKLI VVI FPS GGE RYLLS TELFES VRYEAENLPVE. . AAAAI QVAKRPEN. AGKLI AVVF PS F GERYLS TQLFQS I REECEQMOPEL. . . . . . AAAA QVAKPPV A e k g $I$ t vis quyn te ye Irdavklve

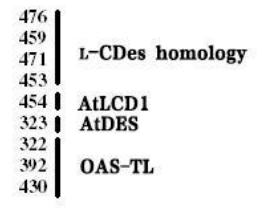

KQETMA

KVLSH.
KVLS QL

KVISN.

$\ldots \ldots$

- n t n

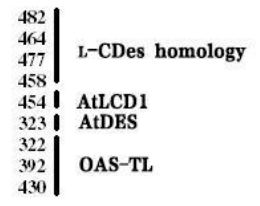

Figure 1. Sequence analysis of CDes, CDes homology, and OAS-TL-A, B, C proteins from the plant. The sequence alignment of L-CDes homology from Oryza sativa (XP_015613237), Panicum miliaceum (RLN24808), Dichanthelium oligosanthes (OEL32418), and Zea mays (PWZ10688) and AtLCD1 (NP_001327694), AtDES (OAO92103), OAS-TL-A (AEE83514), OASTL-B (AEC10318), and OAS-TL-C (AEE79963) from Arabidopsis thaliana was created by DNAMAN with default parameter. Amino acids with blue, black, and gray backgrounds indicate completely or highly conserved residues. The PLP binding sites are shown with a black box, the substrates binding sites of OAS-TL are shown with a red box. 
A

B

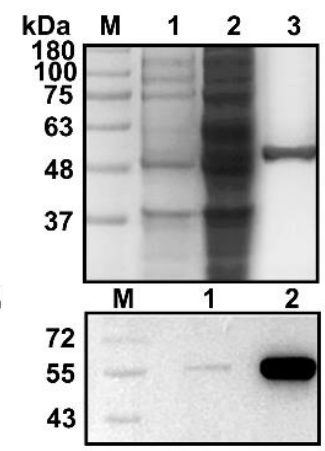

C

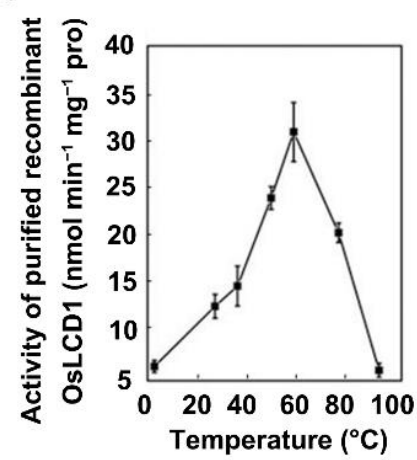

D

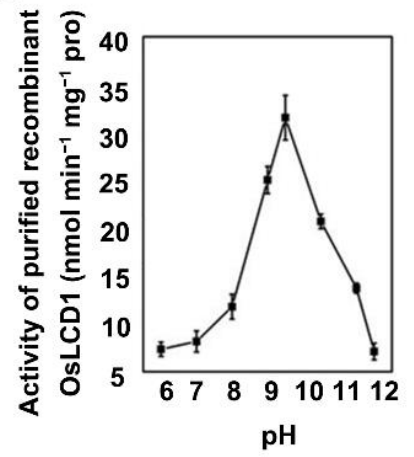

Figure 2. Biochemical characterization of purified recombinant His-tagged OsLCD1 expressed in E. coli. (A) Expression and purification of OsLCD1 recombinant protein. OsLCD1 expression was induced with $0.2 \mathrm{mM}$ IPTG for $12 \mathrm{~h}$ and then purified by Ni-affinity chromatography. M: Molecular marker; Lane1: Total protein without IPTG induction of BL21(DE3)//pET28 $\alpha$-OsLCD1; Lane2 total protein after IPTG induction of BL21(DE3)/ $p E T 28 \alpha$-OsLCD1; Lane3: Expressed protein purified by Ni-affinity chromatography. (B) Western blot of purified OsLCD1 recombinant protein. M: Molecular marker; Lane1: immunoblot of purified protein developed with the polyclonal antiserum against the putative OsLCD1 eluted by NTA-50 buffer; Lane2: immunoblot of purified protein developed with the polyclonal antiserum against the putative OsLCD1 eluted by NTA-50 buffer NTA-100. (C,D) Temperature and $\mathrm{pH}$ dependence of the OsLCD1 reaction. Data shown are means $\pm \mathrm{SD}$ from three independent measurements.

Table 1. The purification and catalytic activity of OsLCD1 expressed in E. coli. The recombinant His-tagged OsLCD1 protein was purified using the Ni-NTA Purification System. CDes and OAS-TL activities were measured as described.

\begin{tabular}{cccccc}
\hline Purification Step & $\begin{array}{c}\text { Protein } \\
(\mathbf{m g})\end{array}$ & $\begin{array}{c}\text { Specific Activity } \\
\text { (nmol } \mathbf{~ m i n}^{-\mathbf{1}} \mathbf{~ m g}^{-\mathbf{1}} \text { pro) } \\
\text { CDes OAS-TL }\end{array}$ & $\begin{array}{c}\text { Total Activity } \\
\text { (nmol min-1) } \\
\text { CDes OAS-TL }\end{array}$ & $\begin{array}{c}\text { Purification Factor } \\
\text { CDes OAS-TL }\end{array}$ & $\begin{array}{c}\text { Yield (\%) } \\
\text { CDes OAS-TL }\end{array}$ \\
\hline Crude extract & 1.15 & $8.021 .90 \times 10^{3}$ & $9.222 .77 \times 10^{3}$ & -- & - \\
\hline $\begin{array}{c}\text { Ni-NTA } \\
\text { chromatography }\end{array}$ & 0.14 & $23.930 .72 \times 10^{3}$ & $3.350 .13 \times 10^{3}$ & 2.980 .38 & 36.334 .69 \\
\hline
\end{tabular}

Table 2. Catalytic properties of the recombinant His-tagged OsLCD1 for the CDes and OAS-TL enzymatic reactions. L-Cys was used as a substrate for the DES reaction, whereas OAS and $\mathrm{Na}_{2} \mathrm{~S}$ were used as co-substrates for the OAS-TL reaction. Lineweaver-Burk plot was performed to calculate the kinetic constants.

\begin{tabular}{|c|c|c|c|c|}
\hline Km (mM Cys) & $\begin{array}{c}\text { Vmax } \\
\left(\mu \mathrm{mol} \mathrm{H}_{2} \mathrm{~S} \min ^{-1} \mathrm{mg}^{-1} \text { pro }\right)\end{array}$ & Km (mM OAS) & $\mathrm{Km}\left(\mathrm{mM} \mathrm{Na} \mathrm{N}_{2} \mathrm{~S}\right)$ & $\begin{array}{c}\text { Vmax } \\
\left(\mu \mathrm{mol} \mathrm{L-Cys} \min ^{-1} \mathrm{mg}^{-1} \text { pro }\right)\end{array}$ \\
\hline $0.15 \pm 0.02$ & $0.04 \pm 0.01$ & $3.76 \pm 0.41$ & $8.13 \pm 0.72$ & $1.76 \pm 0.32$ \\
\hline
\end{tabular}

\subsection{Overexpression of OsLCD1 Enhance Endogenous $\mathrm{H}_{2} \mathrm{~S}$ Production and Drought Tolerance in Rice}

To investigate the physiological role of OsLCD1 in rice, two independent 35S:OsLCD1GFP overexpression lines (OX1 and OX2) were generated by introducing the $p C A M B I A 1305$ OsLCD1-GFP expression construct into Wuyunjing 7. Firstly, the overexpression of OsLCD1 was confirmed by immunoblot analysis. The results showed that the band signal of OsLCD1-GFP was detected in protein extracts from both two transgenic lines, but not wild-type (cv. Wuyunjing 7) (Figure 3A). Furthermore, biochemical characterization results revealed that the total LCD activity in OX1 and OX2 was increased by $43.7 \%$ and $71.8 \%$ compared to the wild-type plants (Figure 3B). This result further confirms that the LCD1 protein is a true LCD enzyme. Accordingly, the endogenous $\mathrm{H}_{2} \mathrm{~S}$ content in $\mathrm{OX} 1$ and OX2 was about $47.5 \%$ and $102.1 \%$ higher than those of wild-type plants (Figure 3C). 
A

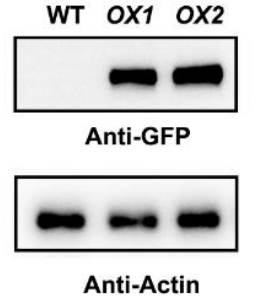

D

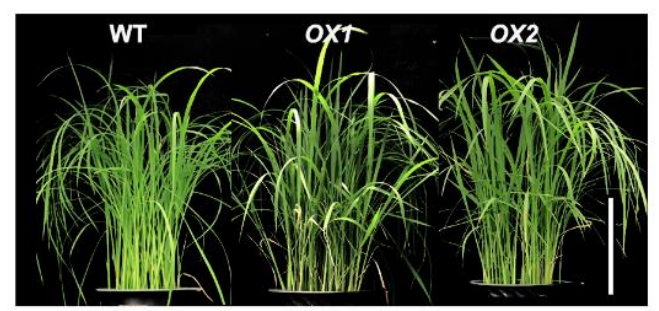

Con

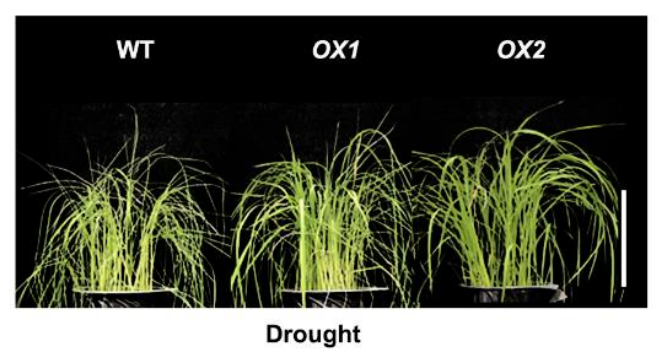

B

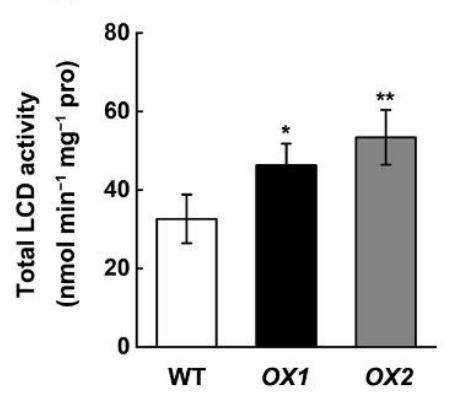

C

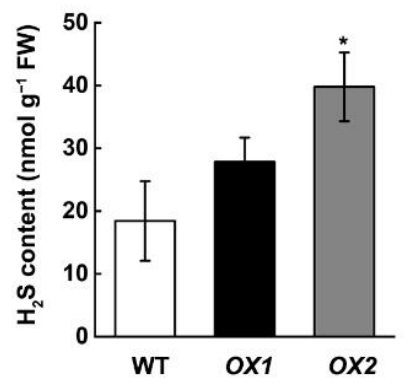

E
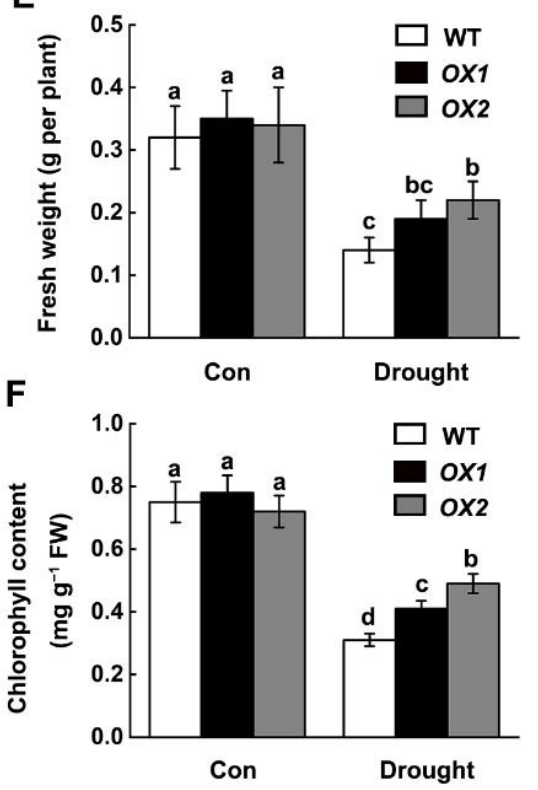

Figure 3. Overexpression of OsLCD1 enhances rice drought tolerance. (A) Identification of 35S:OsLCD1-GFP overexpression lines. The total protein from two independent overexpression lines (OX1 and OX2) and wild-type (cv. Wuyunjing 7, WT) was extracted and was analyzed by immunoblotting with an anti-GFP antibody. $(\mathbf{B}, \mathbf{C})$ Overexpression of OsLCD1 increases LCD activity and $\mathrm{H}_{2} \mathrm{~S}$ production in 14-day-old rice plants. (D) Drought stress tolerance assay. Well-irrigated 14-day-old wild-type, $O X 1$, and $O X 2$ rice seedlings were exposed to drought stress by withholding water for 6 days. Pictures were then taken. Scale bar $=10 \mathrm{~cm}$. $(\mathbf{E}, \mathbf{F})$ The related fresh weight and chlorophyll content were determined. Data are means $\pm \mathrm{SD}(n=3)$. Statistical comparisons were performed by independent samples $t$-test (two-tailed) between leaves from wild-type and OsLCD1 overexpression lines $\left({ }^{*} p<0.05,{ }^{* *} p<0.01\right)$. Different lower case letters indicate significant differences at $p<0.05$ (one-way ANOVA, Duncan's multiple range tests).

Our previous study has shown that exogenous $\mathrm{H}_{2} \mathrm{~S}$ could alleviate rice drought stress [13]. We then wonder whether the overexpression of OsLCD1 would affect rice drought tolerance. Thus, two-week-old rice seedlings (WT, OX1, and OX2) were subjected to drought stress for 10 days. We observed that overexpression of OsLCD1 significantly improved the growth performance of rice seedlings under drought stress (Figure 3D). Compared with the wild type, the fresh weight was increased by $29 \%$ and $36 \%$ (Figure 3E), and the chlorophyll content was increased by $28 \%$ and $39 \%$ in OX1 and OX2 plants (Figure 3F), respectively. These results indicated that overexpression of OSLCD1 improves rice drought tolerance.

To investigate the molecular mechanism of OsLCD1 in response to drought stress, the expression profiles of genes involved in drought stress response were determined. RT-qPCR results showed that the transcript of genes encoding antioxidant enzymes, including ascorbate peroxidase 2 (APX2) and catalase (CATA), and a basic leucine zipper (bZIP) 
transcription factor 23 (bZIP23) and a dehydration responsive element-binding protein (DREB) were increased by drought stress in wild-type plants, while this induction was further enhanced in OX2 plant (Figure S2). These results indicated that overexpression of OsLCD1 may improve rice drought tolerance via modulating the expression of genes involved in drought stress response.

$\mathrm{H}_{2} \mathrm{~S}$-mediated persulfidation has been reported that regulate diverse cellular signaling pathways [9]. To investigate whether overexpression of OsLCD1 affects the protein persulfidation level in rice seedlings, we determined the persulfidation level of total protein from wild-type OX1 and OX2 plants under normal and drought stress conditions. A tag-switch assay in which persulfidated Cys was labeled with cyan-biotin and could specifically be detected by anti-biotin immunoblot analysis was used [23,24]. The immunoblotting results showed that drought stress significantly enhanced the protein persulfidation level in all rice plants, while the protein persulfidation level was higher in $O X 1$ and $O X 2$ compared with wild-type (Figure 4). These results indicated that OsLCD1-mediated persulfidation may involve in rice drought tolerance.

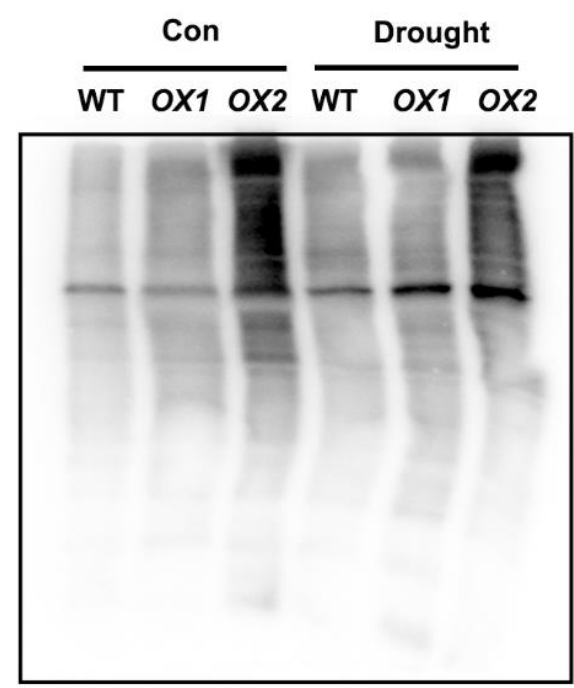

Anti-Biotin

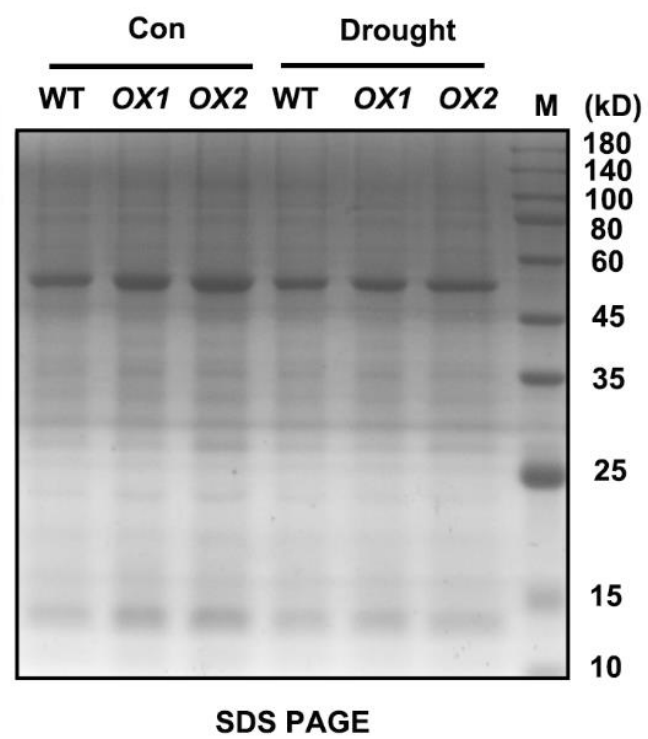

SDS PAGE

Figure 4. OsLCD1-mediated persulfidation of rice total protein. Fourteen-day-old rice seedlings of wild-type (cv. Wuyunjing 7, WT), OX1, and OX2 were isolated from cultivated culture and placed in filter paper for dehydration for $3 \mathrm{~h}$. Afterward, proteins were extracted from $0.2 \mathrm{~g}$ of leaves and subjected to the modified biotin switch method, and the labeled proteins were detected using protein blot analysis with antibodies against biotin. Coomassie brilliant blue-stained gels were presented to show that equal amounts of proteins were loaded. Numbers on the right of the panels indicate the position of the protein markers in $\mathrm{kDa}$.

\subsection{Dehydration-Triggered Inhibition of NR Activity Was Correlated with Endogenous $\mathrm{H}_{2} \mathrm{~S}$ Content}

Previous studies revealed that NR plays an important role in plant stress response [31]. To investigate whether NR is involved in the endogenous $\mathrm{H}_{2} \mathrm{~S}$-enhanced rice drought tolerance, we detected the changes of NR activity in rice leaves in response to drought stress. In comparison with the control plants, NR activity was decreased in rice seedling leaves after dehydration (Figure 5A). For example, NR activity was rapidly decreased by $33.3 \%$ within $1 \mathrm{~h}$ after dehydration and unchanged until $3 \mathrm{~h}$, and then further decreased by $67.2 \%$ at $6 \mathrm{~h}$. The changes in NR activity showed the opposite tendency with endogenous $\mathrm{H}_{2} \mathrm{~S}$ production in response to dehydration stress [13]. Meanwhile, the pretreatment of $\mathrm{NaHS}$ reinforced the decrease in NR activity after dehydration, indicating that dehydrationtriggered inhibition of NR activity may regulate by endogenous $\mathrm{H}_{2} \mathrm{~S}$ (Figure 5B). To further verify this, hypotaurine (HT, a $\mathrm{H}_{2} \mathrm{~S}$ scavenger) [32] or DL-propargylglycine (PAG, an L-DES inhibitor) [33] was used. With respect to the rapidly decreased NR activity in response 
to dehydration stress by exogenous application of NaHS, pretreated with HT or PAG significantly alleviated dehydration-induced inhibition of NR activity (Figure 5C,D). Thus, these results clearly indicated that dehydration-triggered inhibition of NR activity was correlated with endogenous $\mathrm{H}_{2} \mathrm{~S}$ content.

A
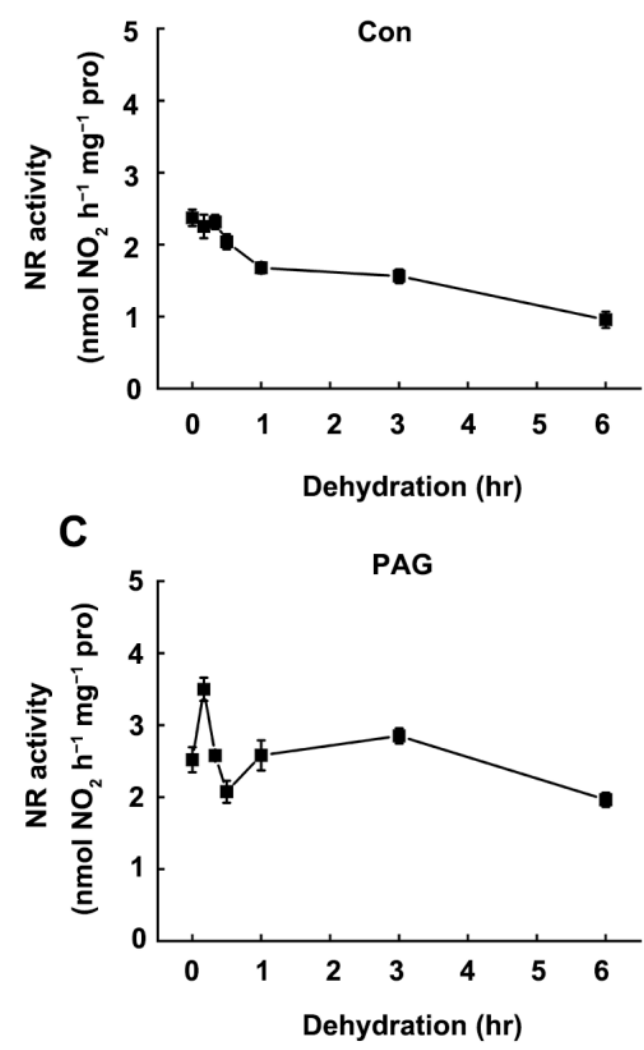

B

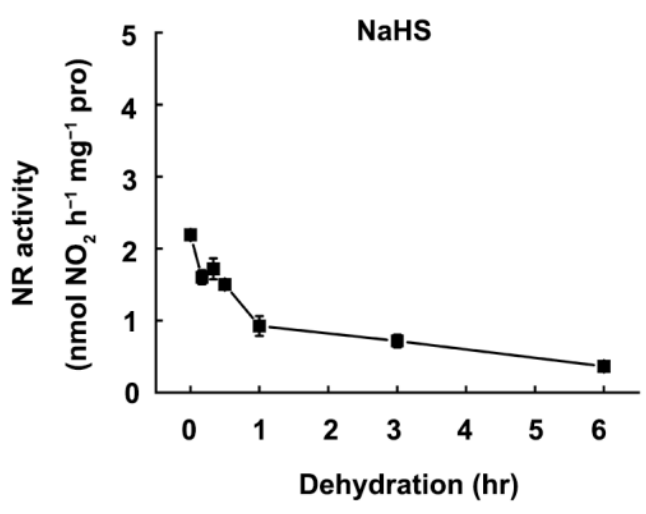

D

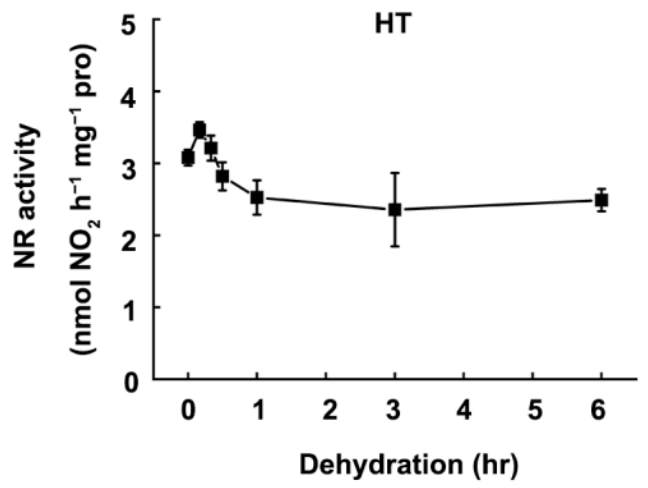

Figure 5. Regulation of NR activity by $\mathrm{H}_{2} \mathrm{~S}$. The 14-day-old rice seedlings cultured under normal conditions (A) or retreated with NaHS (100 uM, B), PAG (1 mM, C), or HT (1 mM D). For the dehydration time-course experiment, Leaf blade branches were isolated from cultivated soil and placed in filter paper. The leaves samples were harvested, and the total NR activity was measured at indicated time points. Data are means $\pm \mathrm{SD}(n=3)$.

To determine whether the decreased NR activity was caused by transcriptional level regulation or post-translational modification, the expression profiles of genes encoding NR were verified. In rice, there are two NR encoding genes, NIA1 and NIA2. The RT-qPCR result showed that the transcripts level of both NIA1 and NIA2 was gradually decreased in rice seedling leaves after dehydration (Figure 6A,B). However, pretreatment of NaHS has no significant effect on the dehydration-inhibited gene expression of NIA1 and NIA2, indicating $\mathrm{H}_{2} \mathrm{~S}$ may regulate $\mathrm{NR}$ activity at the post-translational level. 
A

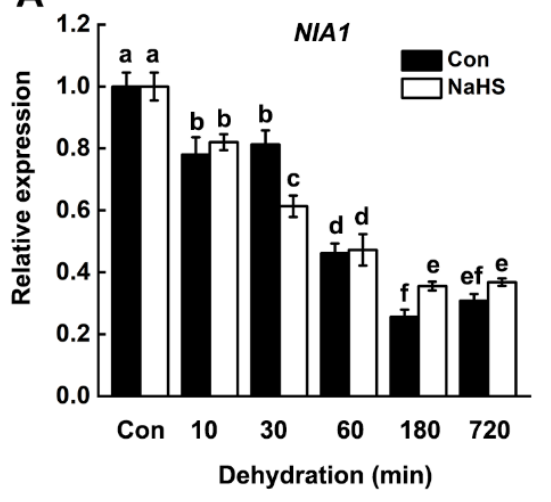

C

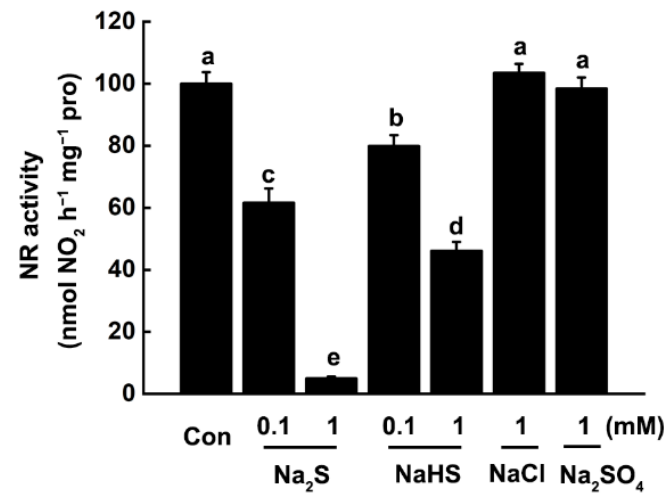

D

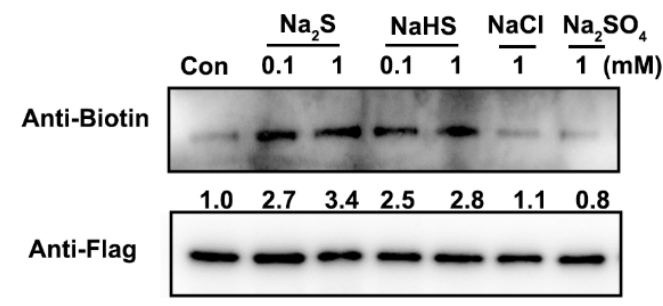

B

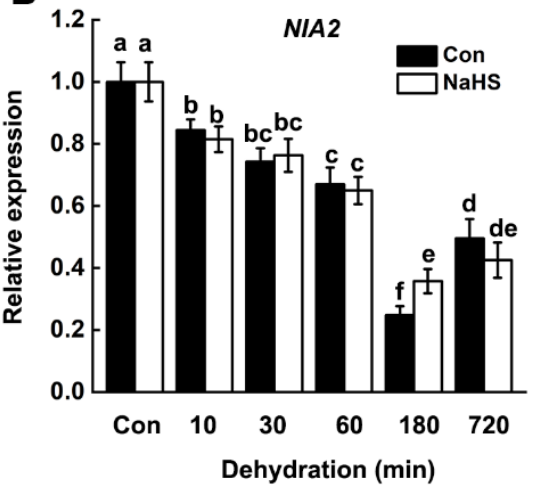

E

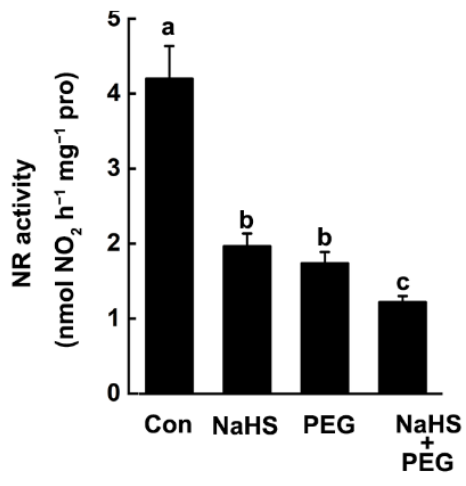

$\mathbf{F}$

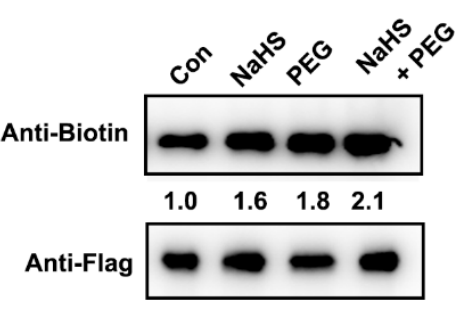

Figure 6. $\mathrm{H}_{2} \mathrm{~S}$-mediated persulfidation inhibits $\mathrm{NR}$ activity in response to drought stress. $(\mathbf{A}, \mathbf{B})$ Time-course expression profiles of NIA1 and NIA2 in rice seedlings pretreated with or without NaHS followed by dehydration. Fourteen-day-old wild-type (cv. Wuyunjing 7, WT) rice seedlings were pretreated with or without NaHS $(100 \mu \mathrm{M})$ for $2 \mathrm{~h}$ and then placed in filter paper for dehydration treatment to mimic drought stress. Leaves were harvested for RT-qPCR analysis at the indicated time point. Expression levels are relative to corresponding untreated wild-type samples (control) after normalization to reference genes of OsActin1 and OsActin2. (C) Persulfidation inhibits NIA2-related NR activity in tobacco. N. benthamiana leaves were transiently overexpressed 35S:NIA2-Flag construct. Total proteins were extracted, and NIA2-Flag protein was harvested by immunoprecipitation with anti-Flag agarose beads. NIA2-Flag protein-related NR activity was detected after being treated with or without different sulfur-containing chemicals for $30 \mathrm{~min}$. (D) The persulfidation level of NIA2-Flag protein from (C) was analyzed by immunoblotting with an anti-Biotin and anti-Flag antibody. The persulfidation levels are relative to corresponding untreated control samples after normalization to the anti-Flag signal abundance. (E) Persulfidation-inhibited NIA2-related NR activity upon osmotic stress in rice. Rice protoplasts of the nia2 mutant (cv. Dongjin) were transfected with 35S:NIA2-Flag. After $12 \mathrm{~h}$ incubation, protoplasts were treated with or without NaHS $(100 \mu \mathrm{M})$ in the absence or presence of PEG6000 (10\%) for $1 \mathrm{~h}$. Total proteins were extracted for the determination of NR activity. (F) The persulfidation level of protein from (E) was analyzed by immunoblotting with an anti-Biotin and anti-Flag antibody. The related persulfidation level is relative to corresponding untreated control samples after normalization to the anti-Flag signal abundance. Data are means $\pm \mathrm{SD}(n=3)$. Lower case letters indicate significant differences at $p<0.05$ (Duncan's multiple range tests). 


\section{4. $\mathrm{H}_{2} \mathrm{~S}$-Mediated Persulfidation-Inhibited NR Activity}

It is plausible that $\mathrm{NR}$ activity was regulated by $\mathrm{H}_{2} \mathrm{~S}$-mediated persulfidation. Subsequently, we determine the effects of the exogenous application of $\mathrm{H}_{2} \mathrm{~S}$ donors on NR activity. In rice, the transcriptional level of NIA2 is markedly higher than that of NIA1, and NIA2 mutation causes more than $90 \%$ loss in NR activity [34,35]. Thus, we first clone the rice NIA2 gene and transiently overexpressed 35S:NIA2-Flag construct in N. benthamiana leaves. After $12 \mathrm{~h}$ incubation, the NIA2 protein was immunoprecipitated by using an anti-Flag antibody and treated with different $\mathrm{H}_{2} \mathrm{~S}$ donors. The results showed that treatment of both well-known $\mathrm{H}_{2} \mathrm{~S}$ donors, $\mathrm{NaHS}$ and $\mathrm{Na}_{2} \mathrm{~S}$, significantly decreased NR activity (Figure 6C). When $1 \mathrm{mM} \mathrm{NaHS}$ was applied, the NR activity was decreased by $55 \%$, while $1 \mathrm{mM} \mathrm{Na}_{2} \mathrm{~S}$ caused a $93 \%$ loss in NR activity. It should be mentioned that treatment with $\mathrm{NaCl}$ or $\mathrm{Na}_{2} \mathrm{SO}_{4}$ fails to reduce the $\mathrm{NR}$ activity. These results suggested that $\mathrm{H}_{2} \mathrm{~S}$ or $\mathrm{HS}^{-}$, rather than other compounds regulates the NR activity. These changes in NR activity were consistent with the corresponding persulfidation level of NIA2, which was enhanced by both $\mathrm{H}_{2} \mathrm{~S}$ donors rather than $\mathrm{NaCl}$ or $\mathrm{Na}_{2} \mathrm{SO}_{4}$ (Figure 6D).

To determine whether NIA2 could be persulfidated in vivo, the protoplasts from nia2 rice mutant (cv. Dongin) with transiently overexpressed 35S:NIA2-Flag were treated with or without NaHS in the presence or absence of polyethylene glycol (PEG), which further mimic drought stress. As expected, immunoblotting results showed that NIA2 protein was persulfidated in rice protoplasts, and NaHS pretreatment enhanced its persulfidation level (Figure 6E). Importantly, the persulfidation of NIA2 protein was significantly enhanced by PEG treatment, while this could be further strengthened by NaHS. These results on the persulfidation level of NIA2 protein were consistent with the changes in their enzymatic activity (Figure 6F), indicating that dehydration-triggered inhibition of NR activity was controlled by $\mathrm{H}_{2} \mathrm{~S}$-mediated persulfidation.

In order to validate the contribution of OsLCD1 in PEG-induced NIA2 persulfidation, we examined the persulfidation level of NIA2 protein in wild-type (cv. Wuyunjing 7, WT) and 35S:OsLCD1-GFP overexpression rice plants (OX2). With this aim in mind, the 35S:NIA2-Flag construct was separately transiently expressed into protoplasts of wild type and 35S:OsLCD1-GFP overexpression line (OX2). The immunoblotting result showed that PEG treatment induced the persulfidation of NIA2 protein in protoplasts of wild type, while this was further intensified in the OX2 line (Figure 7A). Moreover, we found that the NR activity was decreased faster in the OX2 line as compared to wild-type plants upon the dehydration stress (Figure 7B). These results demonstrated that persulfidation-mediated inhibition of NR activity may confer rice drought tolerance.

\subsection{Knock down of NIA2 Enhances Rice Drought Tolerance}

To investigate the biological role of NR inhibition in rice drought stress response, drought stress tolerance of wild-type and nia 2 mutant was compared. We observed that mutation of NIA2 significantly improved the growth performance of rice seedlings under drought stress (Figure 8A). Compared with the wild-type (cv. Dongjin, WT), the fresh weight was increased by $36 \%$ and $29 \%$ (Figure $8 \mathrm{~B}$ ), as the chlorophyll content was increased by $39 \%$ in the nia 2 plant (Figure 8 C), respectively. These results indicated that mutation of NIA2 improves rice drought tolerance. 
A

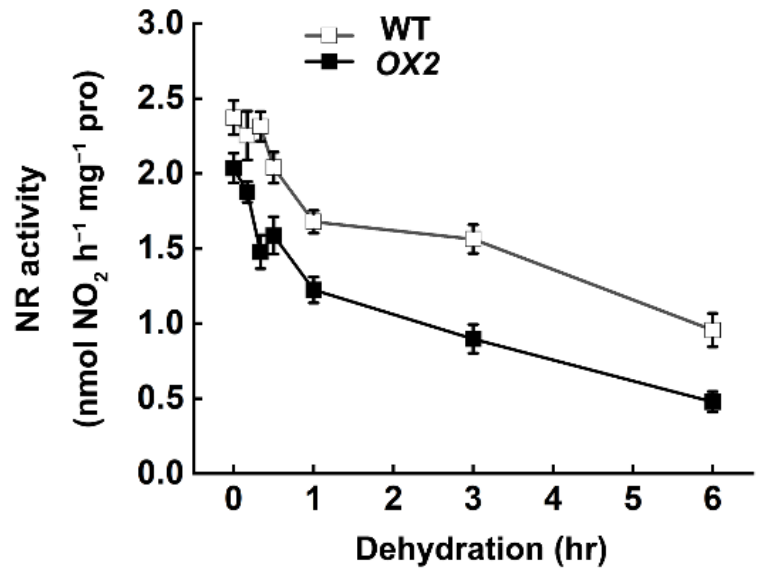

B

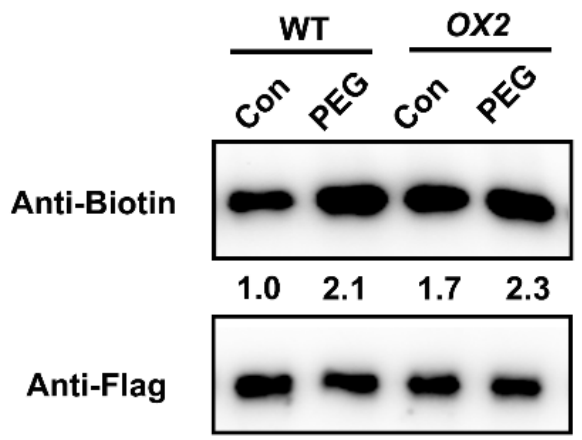

Figure 7. Overexpression of OsLCD1 enhances persulfidation and the activity decrease in NR. (A) Dehydration-inhibited NR activity. The 14-day-old wild-type (cv. Wuyunjing 7, WT) and OX2 rice seedlings were cultured under normal conditions. For the dehydration time-course experiment, leaf blade branches were isolated from cultivated soil and placed in filter paper. The leaves samples were harvested, and the total NR activity was measured at indicated time points. Data are means \pm $\mathrm{SD}(n=3)$. (B) Wild-type and OX2 rice protoplasts with transiently expressed NIA2-Flag were treated with or without $100 \mu \mathrm{M}$ NaHS in the absence or presence of 10\% PEG6000 $1 \mathrm{~h}$, and then the total proteins were extracted and analyzed by immunoblotting with an anti-Biotin and anti-Flag antibody.

To further investigate the molecular mechanism of NIA2 in response to drought stress, the expression profiles of genes involved in drought stress response in the nia2 mutant were determined. RT-qPCR results showed that the transcript of genes encoding antioxidant enzymes, including APX2 and CATA, were significantly higher in nia2 mutant as compared to wild-type plants upon drought stress (Figure $8 \mathrm{D}, \mathrm{E}$ ). Meanwhile, after drought stress, the induction of $b Z I P 23$ and DREB genes in nia2 mutants was further enhanced compared with the wild type (Figure $8 \mathrm{~F}, \mathrm{G}$ ). Based on these findings, we concluded that NIA2 negatively regulates rice drought tolerance. 
A

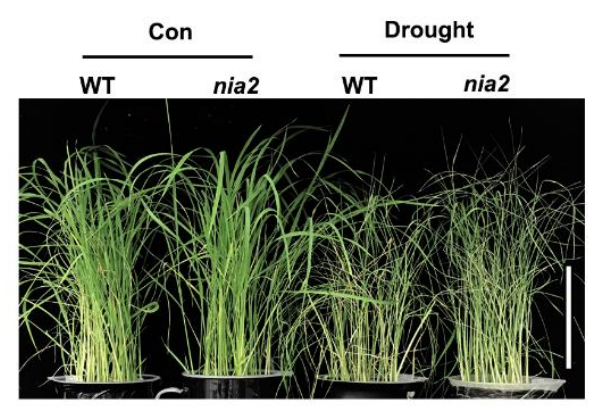

D

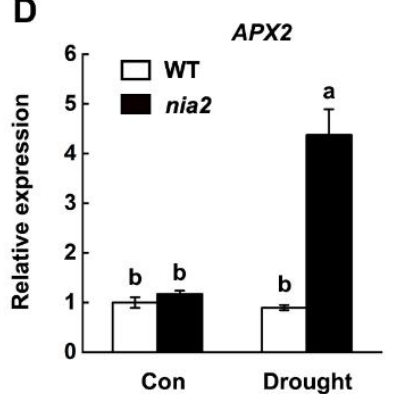

E

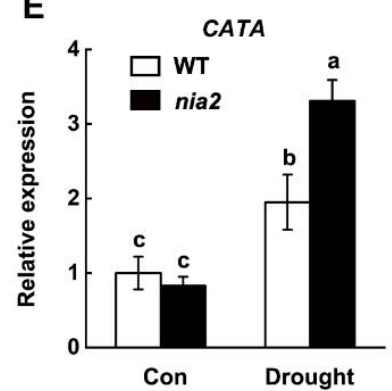

B

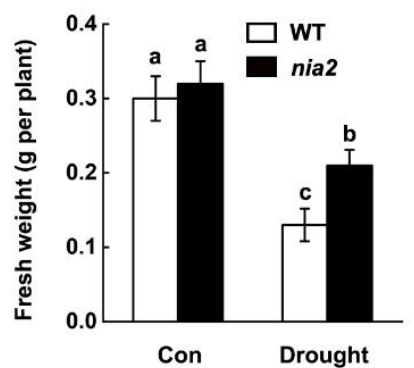

$\mathbf{F}$

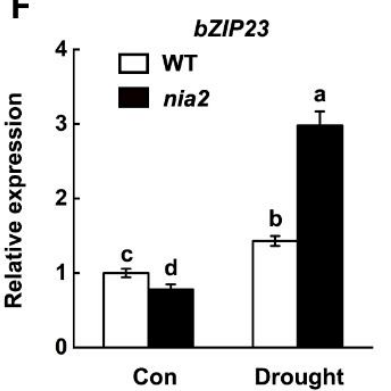

C

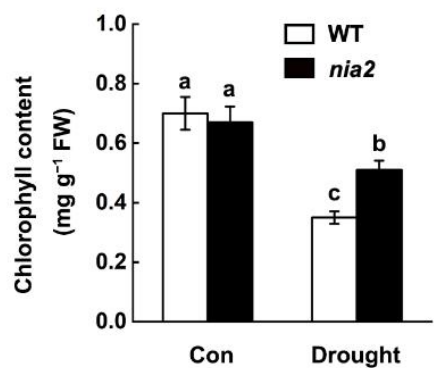

G

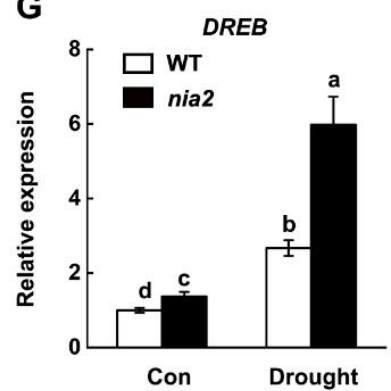

Figure 8. Knockdown of NIA2 enhances rice drought tolerance. (A) Photographs of 14-day-old well-irrigated wild-type (cv. Dongjin, WT) and nia2 mutant rice seedlings were withdrawn from irrigation for 6 days. Scale bar $=10 \mathrm{~cm}$. $(\mathbf{B}, \mathbf{C})$ The related fresh weight and chlorophyll content were determined. (D-G) Relative transcript levels of genes involved in drought stress response in rice seedling leaves were quantified after 4 days of drought stress by qRT-PCR. Expression levels are relative to corresponding untreated wild-type samples (control) after normalization to OsActin1 and OsActin2. Data are means $\pm \mathrm{SD}$ $(n=3)$. Lower case letters indicate significant differences at $p<0.05$ (Duncan's multiple range tests).

\section{Discussion}

\subsection{A True L-Cysteine Desulfhydrase Confers Rice Drought Tolerance}

The importance of cysteine (Cys) in plants is defined not only by its role as an amino acid in primary and secondary metabolisms but also by its function as a metabolic precursor of essential biomolecules [36,37]. In plant cells, $\mathrm{H}_{2} \mathrm{~S}$ is generated through enzymatic pathways that are closely related to Cys metabolism [16]. L-cysteine DESULFHYDRASE (LCD) and D-cysteine DESULFHYDRASE (DCD) degrade L/D-Cys to $\mathrm{H}_{2} \mathrm{~S}$, pyruvate, and ammonia and contribute to the production and biological function of $\mathrm{H}_{2} \mathrm{~S}$ in the cell [38]. Here, we discovered and characterized a rice LCD encoding gene that shares the highest similarity $(56 \%)$ with the AtLCD $[10,39]$. The phylogenetic and homology analysis showed that OsLCD1 is more closely related to the LCD homology proteins from plants rather than the OAS-TL family (Figure 1 and Figure S1).

Up to now, progress has been made in the characterization of the CDes, which usually possess bi-functional activities [9]. For example, the AtDCD1 (At1G48420) was identified as a D-CDes and also possessed ACCD activity [40,41]. AtDCD2 (At3g26115) catalyzes the release of $\mathrm{H}_{2} \mathrm{~S}$ from D-cysteine as well as L-cysteine [16]. Moreover, due to the reversibility of catalytic reactions, those enzymes sometimes exhibit opposite activities. For example, Arabidopsis DES1, a member of the OAS-TL family, is involved in L-cysteine degradation rather than biosynthesis [18]. By contrast, LCD2, a rice AtLCD homolog, predominantly exhibits cysteine biosynthesis activity and is, therefore, a true cysteine synthetase [21]. Our results showed that the $\mathrm{Km}$ of recombinant OsLCD1 protein for OAS or $\mathrm{Na}_{2} \mathrm{~S}$ in the OAS-TL reaction is 25- or 54-fold higher than that for L-cysteine in LCD-catalytic reaction, indicating OsLCD1 predominantly catalyzes the degradation of L-cysteine and thus is a true LCD (Table 2).

The deduction that OsLCD1 is a true LCD was also supported by the analysis of its overexpression rice plants. The total LCD activity in OX1 and OX2 was increased by $43.7 \%$ and $71.8 \%$ compared to the wild-type plants (Figure 3B). Accordingly, the endogenous 
$\mathrm{H}_{2} \mathrm{~S}$ content in OX1 and OX2 was about $47.5 \%$ and $102.1 \%$ higher than those of wildtype plants (Figure 3C). Previous studies reported the involvement of CDes in drought resistance $[10,11]$. Our result also demonstrated that overexpression of OsLCD1 improves rice drought tolerance (Figure 3D). As the main source of $\mathrm{H}_{2} \mathrm{~S}$ production in plant cells, the biological function of CDes largely relies on $\mathrm{H}_{2} \mathrm{~S}[19,42,43]$. OsLCD1-improved rice drought tolerance may derive from the increase in endogenous $\mathrm{H}_{2} \mathrm{~S}$ content.

\subsection{Molecular Mechanisms Underlying the Effects of $\mathrm{H}_{2} \mathrm{~S}$ on Drought Tolerance}

Numerous biochemical and genetic results have undoubtedly established that the signaling action of $\mathrm{H}_{2} \mathrm{~S}$ in cells through persulfidation has important consequences for many physiological processes in plants [22,43,44]. Here, we found that the persulfidation widely exists in rice proteome under normal conditions and was differentially changed by drought stress (Figure 4). This further indicates that persulfidation may involve in rice drought stress response.

Nitrate reductase (NR) is a key enzyme for nitrogen assimilation and acquisition and plays a central role in plant biology and signaling transduction $[28,45]$. Previous results showed that the NR activity declined rapidly in response to drought stress, indicating NR may act as a negative regulator in plant drought stress response [46]. Most recently, it was reported that suppression of nitrate assimilation by regulating the expression of $N R$ under drought stress could contribute to drought tolerance [47]. Similarly, our results showed that the expression of NR genes (Figure 6A,B) and related NR activity (Figure 5A) were gradually decreased under drought stress, indicating drought stress-induced inhibition of NR activity may attribute to the transcription regulation. These results were consistent with a previous study in maize leaves, which shows the decrease in maximal extractable NR activity was accompanied by a decrease in NR transcripts [46]. However, we observed that along with the decrease in NR activity, the endogenous $\mathrm{H}_{2} \mathrm{~S}$ content was gradually decreased after dehydration stress [13], while pretreatment of NaHS could promote the dehydration stress-induced inhibition of NR activity (Figure 5A,B). It indicated that dehydration-triggered inhibition of NR activity may correlate with endogenous $\mathrm{H}_{2} \mathrm{~S}$ content. This deduction was further confirmed by the application of $\mathrm{H}_{2} \mathrm{~S}$ scavenger, HT and LCD inhibitor, PAG, which delay or attenuate the inhibition of NR activity under dehydration stress (Figure 5C,D). Moreover, pretreatment of NaHS has no significant effect on the abundance of NIA1 and NIA2 (Figure 6B), illustrating that $\mathrm{H}_{2} \mathrm{~S}$-promoted inhibition of NR activity may occur at the post-translational level.

NR is a highly regulated enzyme that is regulated at a variety of levels, including transcriptional-level regulation and post-translational modification in response to various environmental stimuli. For instance, the activity of NR in plants changes rapidly in response to various environmental stimuli, such as nitrate, light, plant hormones, low temperature, and drought stress [46,48-50]. Recent study on the interplay of persulfidation and phosphorylation of SnRK2.6 in Arabidopsis stomata regulation and drought tolerance [51] provide a good example for understanding the regulatory mechanism of NR in response to environmental stimuli. Previous studies demonstrated that NR activity was controlled by phosphorylation/dephosphorylation in plant cells. This regulatory model allows the NR transformation between high activity and low activity state [52,53]. Interestingly, both NIA1 and NIA2 protein was found in the Arabidopsis persulfidation proteome [23], revealing a new regulatory mechanism for NR functions. Here, our study showed that the persulfidation modification was detected in the OsNIA2 protein (Figure 6D,F), which is responsible for more than $90 \%$ NR activity in rice [35]. Drought stress significantly induced persulfidation of NIA2 protein, while this could be further enhanced by NaHS pretreatment or overexpression of OsLCD1 (Figures 6F and 7B). The drought stress or NaHS treatment triggers the persulfidation of NIA2 protein and thus inhibits its activity. These results demonstrated that $\mathrm{NR}$ activity was also controlled by $\mathrm{H}_{2} \mathrm{~S}$-mediated persulfidation in response to drought stress. 
Rice seedlings grown in nitrate-deficient conditions are more tolerant to drought stress than of nitrate-sufficient conditions, indicating that decreased nitrogen assimilation contributes to the drought tolerance of rice [47]. This could be a strategy for plants balancing growth and defense responses under stress conditions. Consistently, the lossof-function mutants of OsNR1.2 [47] and nia2 mutant, which both impaired nitrogen assimilation, are more tolerant to drought stress (Figure 8). A zinc finger transcription factor DROUGHT AND SALT TOLERANCE (DST) was specifically responsible for the suppression of OsNR1.2 expression, but not OsNIA2 in response to drought stress. As a consequence, osnr1.2 mutant plants exhibited similar enhanced stomatal closure and drought tolerance as $d s t$ mutant plants. As the side reaction during NR-catalyzed nitrogen assimilation, the production of $\mathrm{NO}$, an important signaling molecule, also contributed to the biological function of NR [31]. However, Since NO-deficient plants are markedly resistant to water deficit, the reduced water losses in NO-deficient plants may be due to hypersensitivity to $\mathrm{ABA}$, thus leading to NO-independent inhibition of stomata opening and enhanced closure by ABA. In Arabidopsis, ABA-mediated regulation of stomata closure may not be necessarily dependent on de novo biosynthesis of NO through any of the proposed NR-mediated pathways [30]. In our study, the enhanced expression of ABAresponsive genes in the nia2 mutant was observed (Figure $8 \mathrm{~F}, \mathrm{G}$ ), further confirming the importance of the NO-independent pathway in plants' response to drought stress.

Thus, the effects of $\mathrm{H}_{2} \mathrm{~S}$-mediated persulfidation on NIA2 suggest a new mechanism for the modification of the NR protein itself in response to drought stress. More importantly, our results indicated that $\mathrm{H}_{2} \mathrm{~S}$ regulates signaling pathways in response to drought stress through persulfidation of NR protein, which led to the faster and more efficient inhibition of NR activity than through transcription regulation. These data provide new information that will benefit future studies on NR functional regulation in plants and expand the biological function of gasotransmitter $\mathrm{H}_{2} \mathrm{~S}$.

\section{Conclusions}

In summary, we cloned and characterized a gene encoding an $\mathrm{H}_{2} \mathrm{~S}$-producing enzyme in rice and named OsLCD1. Overexpression of OsLCD1 results in enhanced endogenous $\mathrm{H}_{2} \mathrm{~S}$ production, persulfidation of total soluble protein, and confers rice drought stress. We further elucidated a key mechanism of OsLCD1/ $\mathrm{H}_{2} \mathrm{~S}$-improved rice drought stress. Upon drought stress, $\mathrm{H}_{2} \mathrm{~S}$ induces persulfidation of NIA2, an NR isoform responsible for the main NR activity, thus decreasing total NR activity in rice. The inhibition of NIA2 activity improved the drought-responsive genes expression and further led to enhancement of drought tolerance in rice, as proved by the nia 2 mutant analysis. Combined with our previous knowledge of $\mathrm{H}_{2} \mathrm{~S}$ beneficial role on plant growth performance under various environmental stresses, our results contribute to the effective use of $\mathrm{H}_{2} \mathrm{~S}$ in agriculture, not only by exogenous administration of $\mathrm{H}_{2} \mathrm{~S}$ donors but also by genetic manipulation regarding $\mathrm{H}_{2} \mathrm{~S}$ metabolic pathways. Moreover, our results shed new light on the understanding of crop genetic improvement strategies through exploring and manipulating the other components that effectively regulate NR activity to balance crop growth/nitrogen assimilation and adaptation to stress.

\section{Materials and Methods}

\subsection{Plant Materials, Growth Condition, and Treatment}

Rice (Oryza sativa L., Wuyunjing 7 [54], and Dongjin [35]) was used in this study. Seeds were surface-sterilized and germinated in distilled water for 2 days at $28{ }^{\circ} \mathrm{C}$. For drought stress experiments, germinated seeds were sowed into a $550 \mathrm{~mL}$ black opaque plastic beaker with soil in the glasshouse. The soil was taken from a field experiment site in Nanjing Agricultural University in Nanjing, Jiangsu. After two weeks, seedlings were withdrawn for irrigation for 8 days. After treatments, the corresponding phenotypes, including fresh weight and chlorophyll content, were measured. 


\subsection{Sequence Alignment and Phylogenetic Analysis}

The alignment and phylogenetic tree of L-CDes homology from Oryza sativa (XP 015613237), Panicum miliaceum (RLN24808), Dichanthelium oligosanthes (OEL32418), and Zea mays (PWZ10688) and AtLCD1 (NP_001327694), AtDES (OAO92103), OAS-TL-A (AEE83514), OAS-TL-B (AEC10318), and OAS-TL-C (AEE79963) from Arabidopsis thaliana was performed and constructed according to the method described previously [8].

\subsection{Cloning, Expression, and Purification of Recombinant OsLCD1}

Total RNA was extracted from leaves of 14-day-old rice plants using Trizol reagent (Invitrogen, Gaithersburg, MD, USA) according to the manufacturer's instructions. The reverse transcription reaction was carried out to obtain cDNA by using the Super Script FirstStrand Synthesis System for RT-PCR (Transgene, Beijing, China). To obtain the putative $L$ CDes1 cDNA from Oryza sativa, the forward primer (5'-ATGGCGTCGATCCCGCCGGAT$\left.3^{\prime}\right)$ and the reverse primer (5'-TCAGGCCATCGTTTCCTGCTTC- $3^{\prime}$ ) were used. The full length of OsLCD1 was introduced into the $p E T-28 a(+)$ vector at the sides of XhoI and BamHI using a homologous recombination technique (Vazyme). After that, the recombinant vector was transferred into E. coli strain Rosetta (DE3) for protein expression. Briefly, the freshly inoculated Rosetta strain was grown at $37^{\circ} \mathrm{C}$ with vigorous shaking for $4 \mathrm{~h}$, at which point the OD600 of the culture was $0.5 \sim 0.6$. Then $0.2 \mathrm{mM}$ isopropyl- $\beta$-D-thiogalactopyranoside (IPTG) was added and cultivated for $12 \mathrm{~h}$ at $16^{\circ} \mathrm{C}$. The purification was performed under non-denaturing conditions by affinity to nickel resin using the Ni-NTA Purification System (Invitrogen) according to the manufacturer's instructions.

\subsection{SDS-PAGE of Recombinant OsLCD1 and Western Blotting}

Recombinant OsLCD1 protein was purified and then subjected to $12.5 \%$ SDS-PAGE. After electrophoresis, the protein was transferred from gel to the polyvinylidene difluoride (PVDF) membrane. The membrane was incubated in phosphate-buffered saline (PBS) with $5 \%$ bovine serum albumin (BSA) for $1 \mathrm{~h}$ at room temperature. After being washed with PBS/Tween buffer three times, immunoblot analysis was performed with relevant antibodies. The anti-His antibody was used at 1:5000 dilution. A secondary antibody was also used at 1:5000 dilution. The bands were visualized using enhanced chemiluminescence (ECL) reagents (Vazyme).

\subsection{Enzyme Activity Measurements}

The OsLCD1 activity was measured by the release of $\mathrm{H}_{2} \mathrm{~S}$ from L-cysteine. The assay contained a total of $3 \mathrm{~mL} 100 \mathrm{mM}$ Tris/ $\mathrm{HCl} \mathrm{pH} \mathrm{8.5,} \mathrm{various} \mathrm{amounts} \mathrm{of} \mathrm{different} \mathrm{protein}$ extracts, and $2.5 \mathrm{mM}$ DTT. The reaction was started by the addition of $1 \mathrm{mM} \mathrm{L}$-cysteine, incubated for $30 \mathrm{~min}$ at $37^{\circ} \mathrm{C}$, and terminated by adding $300 \mu \mathrm{L}$ of $30 \mathrm{mM} \mathrm{FeCl}_{3}$ dissolved in $1.2 \mathrm{~N} \mathrm{HCl}$ and $300 \mu \mathrm{L} 20 \mathrm{mM} \mathrm{N}$,N-dimethyl-pphenylenediamine dihydrochloride dissolved in $7.2 \mathrm{~N} \mathrm{HCl}[55,56]$. The formation of methylene blue was determined at OD670 $\mathrm{nm}$ by using a spectrophotometer. Solutions with different concentrations of $\mathrm{Na}_{2} \mathrm{~S}$ were prepared used for the quantification of the enzymatically formed $\mathrm{H}_{2} \mathrm{~S}$. OAS-TL activity was measured using the method described previously [57] in soluble bacterial or purified protein extracts. Nitrate activity was indicated by active nitrate reductase (NRAact). Briefly, the leaf samples or protoplasts were harvested and ground in the extraction buffer containing $25 \mathrm{mM}$ potassium phosphate buffer ( $\mathrm{pH} 8.8$ ) and $10 \mathrm{mM}$ cysteine. The protein extracted in the presence of excess $\mathrm{Mg}^{2+}$ is considered to be the NRAact in situ in leaf tissues, while NRAmax is measured in the presence and preincubation of EDTA for $30 \mathrm{~min}$. The reaction mixture contained $0.4 \mathrm{~mL}$ of the extracted aliquots, $1.2 \mathrm{~mL}$ of a $0.1 \mathrm{mM}$ potassium phosphate buffer ( $\mathrm{pH} 7.5$ ), $0.1 \mathrm{mM} \mathrm{KNO}_{3}$, and $0.4 \mathrm{~mL}$ of $0.25 \mathrm{mM}$ nicotinamide adenine dinucleotide (NADH). NRA was expressed as $\mu \mathrm{mol} \mathrm{NO}{ }^{2-} \mathrm{g}^{-1} \mathrm{FW} \mathrm{h}^{-1}$. 


\subsection{Construction and Characterization of OsLCD1 Overexpression Lines}

Transgenic lines (OsLCD1 overexpression lines) were generated by Biorun Biotechnology. To obtain the transgenic plants overexpressing OsLCD1, the full-length coding DNA sequence of OsLCD1 was inserted into the plant binary vector $p C A M B I A 1305-G F P$. Then, the OsLCD1 gene under the control of CaMV $35 S$ promoter was transformed into rice (cv. Wuyunjing 7) by the Agrobacterium-mediated transformation method [58]. The progeny was selected by hygromycin and Western blotting with anti-GFP antibodies. Homozygous $\mathrm{T} 3$ seeds of the transgenic plants were used for further analysis.

\subsection{Protoplast Preparation and Transiently Expression of OsNIA2}

Stem and sheath tissues from 100 10-day-old rice seedlings were cut into approximately $0.5 \mathrm{~mm}$ strips and were used for protoplast isolation [59]. The method and details of OsNIA2 gene clone and transient expression in rice protoplast were according to a previous study [60]. Briefly, the 1300221-OsNIA2-Flag plasmid was transfected into $1 \mathrm{~mL}$ rice protoplast from WT, OX2, or nia2 plants using a PEG-calcium-mediated method. After $12 \mathrm{~h}$ incubation, the protoplasts were harvested by centrifugation.

\subsection{Immunochemical Detection of S-Persulfidated Proteins}

S-persulfidated proteins were detected using a modified tag-switch method [23]. The total protein was extracted from rice seedlings with buffer $(25 \mathrm{mM}$ of Tris, $100 \mathrm{mM}$ of $\mathrm{NaCl}, 0.2 \%$ Triton X-100, $\mathrm{pH}$ 8.0). Blocking buffer consisting of $50 \mathrm{mM}$ of methylsulfonylbenzothiazole that was dissolved in tetrahydrofuran was added to an equal amount of extracted protein solutions and was incubated at $37^{\circ} \mathrm{C}$ for $1 \mathrm{~h}$ to block free sulfhydryl groups. Proteins were precipitated by acetone to remove the excess and were resuspended in buffer (50 mM of Tris, 2.5\% (w/v) SDS, $20 \mathrm{mM}$ of CN-biotin, $\mathrm{pH} 8.0)$ and incubated $3 \mathrm{~h}$ at $37^{\circ} \mathrm{C}$. After that, the excess was removed by acetone. The final pellet was resuspended in buffer (50 $\mathrm{mM}$ of Tris, $0.5 \%(w / v)$ SDS, $\mathrm{pH} 8.0$ ). The samples were run on SDS-PAGE and then transferred to a polyvinylidene fluoride membrane. The Western blot was performed with 1:10,000 dilution anti-biotin-HRP (Abcam, Cambridge, MA, USA). Coomassie brilliant blue-stained gels are present to show that equal amounts of proteins were loaded.

\subsection{Real-Time RT-PCR Analysis}

Total RNA was isolated from rice leaves using the Trizol reagent (Invitrogen) according to the manufacturer's instructions. Real-time quantitative reverse-transcription PCR was performed on a Mastercycler ep ${ }^{\circledR}$ realplex real-time PCR system (Eppendorf, Hamburg, Germany) in a $20 \mu \mathrm{L}$ PCR amplification using SYBR ${ }^{\circledR}$ Premix Ex Taq ${ }^{\mathrm{TM}}$ (TaKaRa, San Jose, CA, USA) according to the manufacturer's instructions. Related primers and locus numbers of those genes are shown in Supplementary Table S1. The expression level of target genes was presented as $\mathrm{x}$-fold changes relative to the appropriate control experiment after normalized against that of OsActin1 (LOC_Os03g50890) and OsActin2 (LOC_Os10g36650). Each experiment was performed with three replicates (each biological replicate was measured three times).

\subsection{Statistical Analysis}

Statistical analysis was performed using the software of SPSS 17.0. Statistical comparisons were performed by independent samples $t$-test (two-tailed, ${ }^{*} p<0.05,{ }^{* *} p<0.01$ ). Multiple comparisons were performed using a one-way ANOVA. Differences were considered significant at $p<0.05$. All experimental data are presented as mean $\pm \mathrm{SD}$.

Supplementary Materials: The Supplementary Materials are available online at https:/ /www.mdpi. com/article/10.3390/ijms222212119/s1.

Author Contributions: H.Z. and Y.X. conceived and designed the experiments. H.Z. constructed transgenic plants and performed Western blotting experiments. Y.Z. and F.Z. performed phenotypical and molecular experiments. W.G. cloned, expressed, and characterized OsLCD1 protein. Y.S. 
prepared reagents and data analysis. H.Z., Y.X. and X.Y. wrote the manuscript. All authors have read and agreed to the published version of the manuscript.

Funding: This work was supported by grants from the National Natural Science Foundation of China (32101671, 31670255), the National Natural Science Foundation of China of Jiangsu Province (BK20200561, BK20200282), and the China Postdoctoral Science Foundation (2019M661860).

Institutional Review Board Statement: Not applicable.

Informed Consent Statement: Not applicable.

Acknowledgments: We gratefully acknowledge the assistance of Yali Zhang (State Key Laboratory of Crop Genetics and Germplasm Enhancement, and Key Laboratory of Plant Nutrition and Fertilization in Low-Middle Reaches of the Yangtze River, Ministry of Agriculture, Nanjing Agricultural University, China) in providing the nia2 rice mutant seeds.

Conflicts of Interest: The authors declare that they have no conflict of interest with the contents of this article.

\section{References}

1. Seki, M.; Kamei, A.; Yamaguchi-Shinozaki, K.; Shinozaki, K. Molecular responses to drought, salinity and frost: Common and different paths for plant protection. Curr. Opin. Biotechnol. 2003, 14, 194-199. [CrossRef]

2. Miller, G.; Suzuki, N.; Ciftci-Yilmaz, S.; Mittler, R. Reactive oxygen species homeostasis and signalling during drought and salinity stresses. Plant Cell Environ. 2010, 33, 453-467. [CrossRef]

3. Zhu, J.K. Abiotic stress signaling and responses in plants. Cell 2016, 167, 313-324. [CrossRef]

4. Wang, R. Physiological implications of hydrogen sulfide: A whiff exploration that blossomed. Physiol. Rev. 2012, 92, 791-896. [CrossRef] [PubMed]

5. Corpas, F.J.; González-Gordo, S.; Cañas, A.; Palma, J.M. Nitric oxide and hydrogen sulfide in plants: Which comes first? J. Exp. Bot. 2019, 70, 4391-4404. [CrossRef]

6. Xie, Y.; Zhang, C.; Lai, D.; Sun, Y.; Samma, M.K.; Zhang, J.; Shen, W. Hydrogen sulfide delays GA-triggered programmed cell death in wheat aleurone layers by the modulation of glutathione homeostasis and heme oxygenase-1 expression. J. Plant Physiol. 2014, 171, 53-62. [CrossRef] [PubMed]

7. Guo, H.M.; Xiao, T.Y.; Zhou, H.; Xie, Y.J.; Shen, W.B. Hydrogen sulfide, a versatile regulator of environmental stress in plants. Acta Physiol. Plant 2016, 38, 1-13. [CrossRef]

8. Zhou, H.; Guan, W.; Zhou, M.; Shen, J.; Liu, X.; Wu, D.; Yin, X.; Xie, Y. Cloning and characterization of a gene encoding true D-cysteine desulfhydrase from Oryza Sativa. Plant Mol. Biol. Rep. 2020, 38, 95-113. [CrossRef]

9. Zhang, J.; Zhou, M.; Zhou, H.; Zhao, D.; Gotor, C.; Romero, L.C.; Shen, J.; Ge, Z.; Zhang, Z.; Shen, W.; et al. Hydrogen sulfide, a signaling molecule in plant stress responses. J. Integr. Plant Biol. 2021, 63, 146-160. [CrossRef]

10. Jin, Z.; Xue, S.; Luo, Y.; Tian, B.; Fang, H.; Li, H.; Pei, Y. Hydrogen sulfide interacting with abscisic acid in stomatal regulation responses to drought stress in Arabidopsis. Plant Physiol. Biochem. 2013, 62, 41-46. [CrossRef] [PubMed]

11. Jin, Z.; Wang, Z.; Ma, Q.; Sun, L.; Zhang, L.; Liu, Z.; Liu, D.; Hao, X.; Pei, Y. Hydrogen sulfide mediates ion fluxes inducing stomatal closure in response to drought stress in Arabidopsis thaliana. Plant Soil 2017, 419, 141-152. [CrossRef]

12. Ma, D.; Ding, H.; Wang, C.; Qin, H.; Han, Q.; Hou, J.; Lu, H.; Xie, Y.; Guo, T. Alleviation of drought stress by hydrogen sulfde is partially related to the abscisic acid signaling pathway in wheat. PLoS ONE 2016, 11, 1-16. [CrossRef] [PubMed]

13. Zhou, H.; Chen, Y.; Zhai, F.; Zhang, J.; Zhang, F.; Yuan, X.; Xie, Y. Hydrogen sulfide promotes rice drought tolerance via reestablishing redox homeostasis and activation of ABA biosynthesis and signaling. Plant Physiol. Biochem. 2020, 155, 213-220. [CrossRef] [PubMed]

14. Guo, H.; Zhou, H.; Zhang, J.; Guan, W.; Xu, S.; Shen, W.; Xu, G.; Xie, Y.; Foyer, C.H. L-cysteine desulfhydrase-related $\mathrm{H}_{2} \mathrm{~S}$ production is involved in OSSE5-promoted ammonium tolerance in roots of Oryza sativa. Plant Cell Environ. 2017, 40, 1777-1790. [CrossRef] [PubMed]

15. Rausch, T.; Wachter, A. Sulfur metabolism: A versatile platform for launching defence operations. Trends Plant Sci. 2005, 10, 503-509. [CrossRef]

16. Papenbrock, J.; Riemenschneider, A.; Kamp, A.; Schulz-Vogt, H.N.; Schmidt, A. Characterization of cysteine-degrading and $\mathrm{H}_{2} \mathrm{~S}$-releasing enzymes of higher plants-from the field to the test tube and tack. Plant Biol. 2007, 9, 582-588. [CrossRef] [PubMed]

17. Burandt, P.; Schmidt, A.; Papenbrock, J. Cysteine synthesis and cysteine desulfuration in Arabidopsis plants at different developmental stages and light conditions. Plant Physiol. Biochem. 2001, 9, 861-870. [CrossRef]

18. Álvarez, C.; Calo, L.; Romero, L.C.; García, I.; Gotor, C. An O-acetylserine(thiol)lyase homolog with L-cysteine desulfhydrase activity regulates cysteine homeostasis in Arabidopsis. Plant Physiol. 2010, 152, 656-669. [CrossRef]

19. Zhang, J.; Zhou, M.; Ge, Z.; Shen, J.; Zhou, C.; Gotor, C.; Romero, L.C.; Duan, X.; Liu, X.; Wu, D.; et al. Abscisic acid-triggered guard cell L-cysteine desulfhydrase function and in situ hydrogen sulfide production contributes to heme oxygenase-modulated stomatal closure. Plant Cell Environ. 2020, 43, 624-636. [CrossRef] 
20. Zhang, J.; Zhou, H.; Zhou, M.; Ge, Z.; Zhang, F.; Foyer, C.H.; Yuan, X.; Xie, Y. The coordination of guard-cell autonomous ABA synthesis and DES1 function in situ regulates plant water deficit responses. J. Adv. Res. 2020, 27, 191-197. [CrossRef]

21. Shen, J.; Su, Y.; Zhou, C.; Zhang, F.; Zhou, H.; Liu, X.; Wu, D.; Yin, X.; Xie, Y.; Yuan, X. A putative rice L-cysteine desulfhydrase encodes a true L-cysteine synthase that regulates plant cadmium tolerance. Plant Growth Regul. 2019, 89, 217-226. [CrossRef]

22. Filipovic, M.R. Persulfidation (S-sulfhydration) and $\mathrm{H}_{2}$ S. Handb. Exp. Pharmacol. 2015, 230, 29-59. [PubMed]

23. Aroca, A.; Benito, J.M.; Gotor, C.; Romero, L.C. Persulfidation proteome reveals the regulation of protein function by hydrogen sulfide in diverse biological processes in Arabidopsis. J. Exp. Bot. 2017, 68, 4915-4927. [CrossRef] [PubMed]

24. Filipovic, M.R.; Zivanovic, J.; Alvarez, B.; Banerjee, R. Chemical biology of $\mathrm{H}_{2} \mathrm{~S}$ signaling through persulfidation. Chem. Rev. 2018, 118, 1253-1337. [CrossRef]

25. Jurado-Flores, A.; Romero, L.C.; Gotor, C. Label-free quantitative proteomic analysis of nitrogen starvation in Arabidopsis root reveals new aspects of $\mathrm{H}_{2} \mathrm{~S}$ signaling by protein persulfidation. Antioxidants 2021, 10, 508. [CrossRef] [PubMed]

26. Shen, J.; Zhang, J.; Zhou, M.; Zhou, H.; Cui, B.; Gotor, C.; Romero, L.C.; Fu, L.; Yang, J.; Foyer, C.H.; et al. Persulfdation-based modifcation of cysteine desulfhydrase and the NADPH oxidase RBOHD controls guard cell abscisic acid signaling. Plant Cell 2020, 32, 1000-1017. [CrossRef] [PubMed]

27. Zhou, M.; Zhang, J.; Shen, J.; Zhou, H.; Zhao, D.; Gotor, C.; Romero, L.C.; Fu, L.; Li, Z.; Yang, J.; et al. Hydrogen sulfide-linked persulfidation of ABI4 controls ABA responses through the transactivation of MAPKKK18 in Arabidopsis. Mol. Plant 2021, 14, 921-936. [CrossRef] [PubMed]

28. Chamizo-Ampudia, A.; Sanz-Luque, E.; Llamas, A.; Galvan, A.; Fernandez, E. Nitrate reductase regulates plant nitric oxide homeostasis. Trends Plant Sci. 2017, 22, 163-174. [CrossRef]

29. Fu, Y.F.; Zhang, Z.W.; Yuan, S. Putative connections between nitrate reductase S-nitrosylation and NO synthesis under pathogen attacks and abiotic stresses. Front Plant Sci. 2018, 9, 474. [CrossRef]

30. Lozano-Juste, J.; León, J. Enhanced abscisic acid-mediated responses in nia1nia2noa1-2 triple mutant impaired in NIA/NR- and AtNOA1-dependent nitric oxide biosynthesis in Arabidopsis. Plant Physiol. 2010, 152, 891-903. [CrossRef]

31. Fancy, N.N.; Bahlmann, A.K.; Loake, G.J. Nitric oxide function in plant abiotic stress. Plant Cell Environ. 2017, 40, 462-472. [CrossRef] [PubMed]

32. Ortega, J.A.; Ortega, J.M.; Julian, D. Hypotaurine and sulfhydryl containing antioxidants reduce $\mathrm{H}_{2} \mathrm{~S}$ toxicity in erythrocytes from a marine invertebrate. J. Exp. Biol. 2008, 211, 3816-3825. [CrossRef]

33. Lisjak, M.; Teklic, T.; Wilson, I.D.; Whiteman, M.; Hancock, J.T. Hydrogen sulfide: Environmental factor or signalling molecule. Plant Cell Environ. 2013, 36, 1607-1616. [CrossRef] [PubMed]

34. Cao, Y.; Fan, X.; Sun, S.; Xu, G.; Jiang, H.; Shen, Q. Effect of nitrate on activities and transcript levels of nitrate reductase and glutamine synthetase in rice. Pedosphere 2008, 18, 664-673. [CrossRef]

35. Sun, H.; Bi, Y.; Tao, J.; Huang, S.; Hou, M.; Xue, R.; Liang, Z.; Gu, P.; Yoneyama, K.; Xie, X.; et al. Strigolactones are required for nitric oxide to induce root elongation in response to nitrogen and phosphate deficiencies in rice. Plant Cell Environ. 2016, 39, 1473-1484. [CrossRef] [PubMed]

36. Gruhlke, M.C.; Slusarenko, A.J. The biology of reactive sulfur species (RSS). Plant Physiol. Biochem. 2012, 59, 98-107. [CrossRef] [PubMed]

37. Romero, L.C.; Aroca, M.Á.; Laureano-Marín, A.M.; Moreno, I.; García, I.; Gotor, C. Cysteine and cysteine-related signaling pathways in Arabidopsis thaliana. Mol. Plant 2014, 7, 264-276. [CrossRef]

38. Kopriva, S. Regulation of sulfate assimilation in Arabidopsis and beyond. Ann. Bot. 2006, 97, 479-495. [CrossRef]

39. Shen, J.J.; Qiao, Z.J.; Xing, T.J.; Zhang, L.P.; Liang, Y.L.; Jin, Z.P.; Yang, G.D.; Wang, R.; Pei, Y.X. Cadmium toxicity is alleviated by AtLCD and AtDCD in Escherichia coli. J. Appl. Microbiol. 2012, 113, 130-1138. [CrossRef] [PubMed]

40. Riemenschneider, A.; Wegele, R.; Schmidt, A.; Papenbrock, J. Isolation and characterization of a D-cysteine desulfhydrase protein from Arabidopsis thaliana. FEBS J. 2005, 272, 1291-1304. [CrossRef] [PubMed]

41. McDonnell, L.; Plett, J.M.; Andersson-Gunnerås, S.; Kozela, C.; Dugardeyn, J.; Straeten, D.V.D.; Glick, B.; Undberg, B.; Regan, S. Ethylene levels are regulated by plant encoded 1-inocyclopropane-1-arboxylic acid deaminase. Physiol. Plant 2009, 136, 94-109. [CrossRef] [PubMed]

42. Mei, Y.; Zhao, Y.; Jin, X.; Wang, R.; Xu, N.; Hu, J.; Huang, L.; Guan, R.; Shen, W. L-Cysteine desulfhydrase-dependent hydrogen sulfide is required for methane-induced lateral root formation. Plant Mol. Biol. 2019, 99, 283-298. [CrossRef] [PubMed]

43. Gotor, C.; García, I.; Aroca, Á.; Laureano-Marín, A.M.; Arenas-Alfonseca, L.; Jurado-Flores, A.; Moreno, I.; Romero, L.C. Signaling by hydrogen sulfide and cyanide through post-translational modification. J. Exp. Bot. 2019, 70, 4251-4265. [CrossRef] [PubMed]

44. Aroca, A.; Zhang, J.; Xie, Y.; Romero, L.C.; Gotor, C. Hydrogen sulfide signaling in plant adaptations to adverse conditions: Molecular mechanisms. J. Exp. Bot. 2021, 72, 5893-5904. [CrossRef] [PubMed]

45. Costa-Broseta, Á.; Castillo, M.; León, J. Nitrite Reductase 1 is a target of nitric oxide-mediated post-translational modifications and controls nitrogen flux and growth in Arabidopsis. Int. J. Mol. Sci. 2020, 21, 7270. [CrossRef]

46. Foyer, C.H.; Valadier, M.H.; Migge, A.; Becker, T.W. Drought-induced effects on nitrate reductase activity and mRNA and on the coordination of nitrogen and carbon metabolism in maize leaves. Plant Physiol. 1998, 117, 283-292. [CrossRef] [PubMed]

47. Han, M.L.; Lv, Q.Y.; Zhang, J.; Wang, T.; Zhang, C.X.; Tan, R.J.; Wang, Y.L.; Zhong, L.Y.; Gao, Y.Q.; Chao, Z.F.; et al. Decreasing nitrogen assimilation under drought stress by suppressing DST-mediated activation of Nitrate Reductase 1.2 in rice. Mol. Plant 2021, in press. [CrossRef] 
48. Srivastava, H.S. Regulation of nitrate reductase activity in higher plants. Phytochemistry 1980, 19, 725-733. [CrossRef]

49. Kaiser, W.M.; Kandlbinder, A.; Stoimenova, M.; Glaab, J. Discrepancy between nitrate reduction rates in intact leaves and nitrate reductase activity in leaf extracts: What limits nitrate reduction in situ? Planta 2000, 210, 801-807. [CrossRef]

50. Creighton, M.T.; Sanmartín, M.; Kataya, A.R.A.; Averkina, I.O.; Heidari, B.; Nemie-Feyissa, D.; Sánchez-Serrano, J.J.; Lillo, C. Light regulation of nitrate reductase by catalytic subunits of protein phosphatase 2A. Planta 2017, 246, 701-710. [CrossRef]

51. Chen, S.; Wang, X.; Jia, H.; Li, F.; Ma, Y.; Liesche, J.; Liao, M.; Ding, X.; Liu, C.; Chen, Y.; et al. Persulfidation-induced structural change in SnRK2.6 establishes intramolecular interaction between phosphorylation and persulfidation. Mol. Plant 2021, 14, 1814-1830. [CrossRef] [PubMed]

52. Kaiser, W.M.; Huber, S.C. Post-translational regulation of nitrate reductase: Mechanism, physiological relevance and environmental triggers. J. Exp. Bot. 2001, 52, 1981-1989. [CrossRef] [PubMed]

53. Lillo, C.; Meyer, C.; Lea, U.S.; Provan, F.; Oltedal, S. Mechanism and importance of post-translational regulation of nitrate reductase. J. Exp. Bot. 2004, 55, 1275-1282. [CrossRef] [PubMed]

54. Chen, J.; Liu, X.; Liu, S.; Fan, X.; Zhao, L.; Song, M.; Fan, X.; Xu, G. Co-Overexpression of OsNAR2.1 and OsNRT2.3a increased agronomic nitrogen use efficiency in transgenic rice plants. Front. Plant Sci. 2020, 11, 1245. [CrossRef] [PubMed]

55. Siegel, M. A direct microdetermination for sulfide. Anal. Biochem. 1965, 11, 126-132. [CrossRef]

56. Xie, Y.J.; Lai, D.W.; Mao, Y.; Zhang, W.; Shen, W.B.; Guan, R.Z. Molecular cloning, characterization, and expression analysis of a novel gene encoding L-cysteine desulfhydrase from Brassica napus. Mol. Biotechnol. 2013, 54, 737-746. [CrossRef] [PubMed]

57. Barroso, C.; Vega, J.M.; Gotor, C. A new member of the cytosolic O-acetylserine(thiol)lyase gene family in Arabidopsis thaliana. FEBS Lett. 1995, 363, 1-5. [CrossRef]

58. Hiei, Y.; Ohta, S.; Komari, T.; Kumashiro, T. Efficient transformation of rice (Oryza sativa L.) mediated by Agrobacterium and sequence analysis of the boundaries of the T-DNA. Plant J. 1994, 6, 271-282. [CrossRef]

59. Zhang, Y.; Su, J.; Duan, S.; Ao, Y.; Dai, J.; Liu, J.; Wang, P.; Li, Y.; Liu, B.; Feng, D.; et al. A highly efficient rice green tissue protoplast system for transient gene expression and studying light/chloroplast-related processes. Plant Methods 2011, 7, 30. [CrossRef]

60. Zhou, H.; Wu, H.H.; Zhang, F.; Su, Y.; Guan, W.X.; Xie, Y.J.; Giroldo, J.P.; Shen, W.B. Molecular basis of cerium oxide nanoparticle enhancement of rice salt tolerance and yield. Environ. Sci. Nano 2021. [CrossRef] 